\title{
The membrane-bound flavocytochrome MsrQ is a substrate of the cytosolic flavin reductase Fre in Escherichia coli
}

Christelle Caux ${ }^{\mathrm{a}}$, Bruno Guigliarellib ${ }^{\mathrm{b}}$, Corinne Vivès ${ }^{\mathrm{c}}$, Frédéric Biaso $^{\mathrm{b}}$, Marius

Horeau $^{\mathrm{a}}$, Hawra Hassoune ${ }^{\mathrm{a}}$, Isabelle Petit-Härtlein ${ }^{\mathrm{c}}$, Céline Juillan-Binard ${ }^{\mathrm{c}}$, Stéphane Torelli ${ }^{\mathrm{a}}$, Franck Fieschi ${ }^{\mathrm{c}}$, Vincent Nivière ${ }^{\mathrm{a}^{*}}$

${ }^{\text {a } U n i v . ~ G r e n o b l e ~ A l p e s, ~ C N R S, ~ C E A, ~ I R I G-L C B M, ~ L a b o r a t o i r e ~ d e ~ C h i m i e ~ e t ~ B i o l o g i e ~ d e s ~}$ Métaux, Grenoble, France.* Email: vniviere@cea.fr.

${ }^{\mathrm{b}}$ Aix-Marseille Univ., CNRS, BIP-UMR 7281 Laboratoire de Bioénergétique et Ingénierie des Protéines, Marseille, France.

${ }^{\mathrm{c}}$ Univ. Grenoble Alpes, CNRS, CEA, Institut de Biologie Structurale, Grenoble, France. 


\section{SUMMARY}

MsrPQ is a new type of methionine sulfoxide reductase (Msr) system found in bacteria. It is specifically involved in the repair of periplasmic methionine residues that are oxidized by hypochlorous acid. MsrP is a periplasmic molybdo-enzyme that carries out the Msr activity by itself, whereas MsrQ, an integral membrane bound hemoprotein, acts as the physiological partner of MsrP to provide electrons for catalysis. Although MsrQ, previously called YedZ, has been associated since long to a protein superfamily named FRD (ferric reductase domain), including the eukaryotic NADPH oxidases and STEAP proteins, its biochemical properties are still sparsely documented. In this work, we have investigated the cofactors content of the E.coli MsrQ and its mechanism of reduction by the cytosolic flavin reductase Fre. We showed by EPR spectroscopy that MsrQ contains a single HALS (highlyanisotropic low-spin) b-type heme, located on the periplasmic side of the membrane. We further demonstrated that MsrQ holds a FMN cofactor that occupies the site where a second heme binds in other members of the FDR superfamily, on the cytosolic side of the membrane. EPR spectroscopy indicates that the FMN cofactor can accommodate a radical semiquinone form. The cytosolic flavin reductase Fre was previously shown to reduce the MsrQ heme. Here, we demonstrated that Fre uses the FMN MsrQ cofactor as a substrate to catalyze the electron transfer from cytosolic NADH to the heme. Formation of a specific complex between MsrQ and Fre could favor this unprecedented mechanism, which most likely involves a transfer of the reduced FMN cofactor from the Fre active site to MsrQ. 


\section{INTRODUCTION}

Oxidative damage is a major issue for cellular systems. Protein methionine residues are particularly susceptible to such oxidation to form methionine sulfoxide (Met-SO), with dramatic consequences for protein structures and functions. ${ }^{1}$ Since years, methionine sulfoxide reductases (Msrs) have been described to repair such methionine oxidation by reducing it into the original methionine, and it is well documented that Msrs play an important role in both prokaryotic and eukaryotic cell integrity. ${ }^{2,3}$

Recently, it has been discovered that some bacteria can express an unprecedented type of Msr system, named MsrPQ, able to counteract the toxicity of hypochlorous acid, $\mathrm{HOCl}{ }^{4,5}$ $\mathrm{HOCl}$, the main component of bleach, is a strong oxidant highly toxic for bacteria, and it is especially produced by macrophage and neutrophil cells as the first line of defense of the innate immune system to kill pathogens. ${ }^{6}$ In bacteria, $\mathrm{HOCl}$ mainly targets protein methionine residues, and as it occurs in other oxidative stress conditions, oxidizes them into methionine sulfoxide (Met-SO). ${ }^{6,7}$ Thus, MsrPQ regenerates the Met residues damaged by $\mathrm{HOCl}^{4}$

MsrPQ is unusual in the sense it involves two metalloproteins, namely MsrP and MsrQ, encoded within a same operon. ${ }^{4,5}$ In fact, most Msrs described to date do not contain metals in their active sites, and rather act through the presence of catalytic cysteine residues (thiol-based Msr). ${ }^{2}$ MsrP, previously named YedY, is a periplasmic soluble protein that carries out the Msr activity by itself, with a molybdopterin cofactor in its active site. ${ }^{8}$ It thus catalyzes the two-electron reduction of periplasmic protein Met-SO into methionine. ${ }^{4} \mathrm{MsrQ}$, previously named YedZ, ${ }^{9-11}$ is an integral membrane heminic protein, which was shown to be the specific electron donor to MsrP. ${ }^{4}$ Whereas MsrP has been structurally and functionally well characterized, ${ }^{4,8,12-19}$ showing similarities with the sulfite oxidase molybdenum-enzyme family, biochemical investigations on MsrQ are much less documented. ${ }^{12,20}$

Phylogenetic studies have associated MsrQ with an important protein superfamily with a heme-containing membrane domain named ferric reductase domain (FRD). ${ }^{21}$ This domain is present in bacteria and eukaryotes, with representatives including yeast ferric reductases and NADPH oxidases (NOX/DUOX). ${ }^{21,22}$ The archetype of FRD consists of six transmembrane segments (TM) with two bis-histidine residue motifs, allowing the chelation of two b-type hemes (Figure 1). ${ }^{23}$ Sequence analyses suggested that among the FRD family, MsrQ proteins, together with the eukaryotic STEAP ferric reductases, ${ }^{24,25}$ form a specific group where the first canonical heme-spanning histidine is replaced by an arginine (Figure 1). ${ }^{21}$ In STEAPs, 
the second His ligand associated with this heme binding motif is not conserved (Figure1), predicting the presence of a single transmembrane heme. Accordingly, the presence of one heme in STEAP proteins has been recently confirmed by the cryo-EM 3D structures of STEAP1 and STEAP4. ${ }^{24,25}$ In MsrQ, three His residues are conserved (Figure 1) and it was reported the presence of two hemes in the protein. ${ }^{20}$ These data suggested that in MsrQ one heme is bis-histidine hexa-coordinated with His91 and His164 residues, the second one being penta-coordinated with a single histidine ligand, His $151 .^{20}$

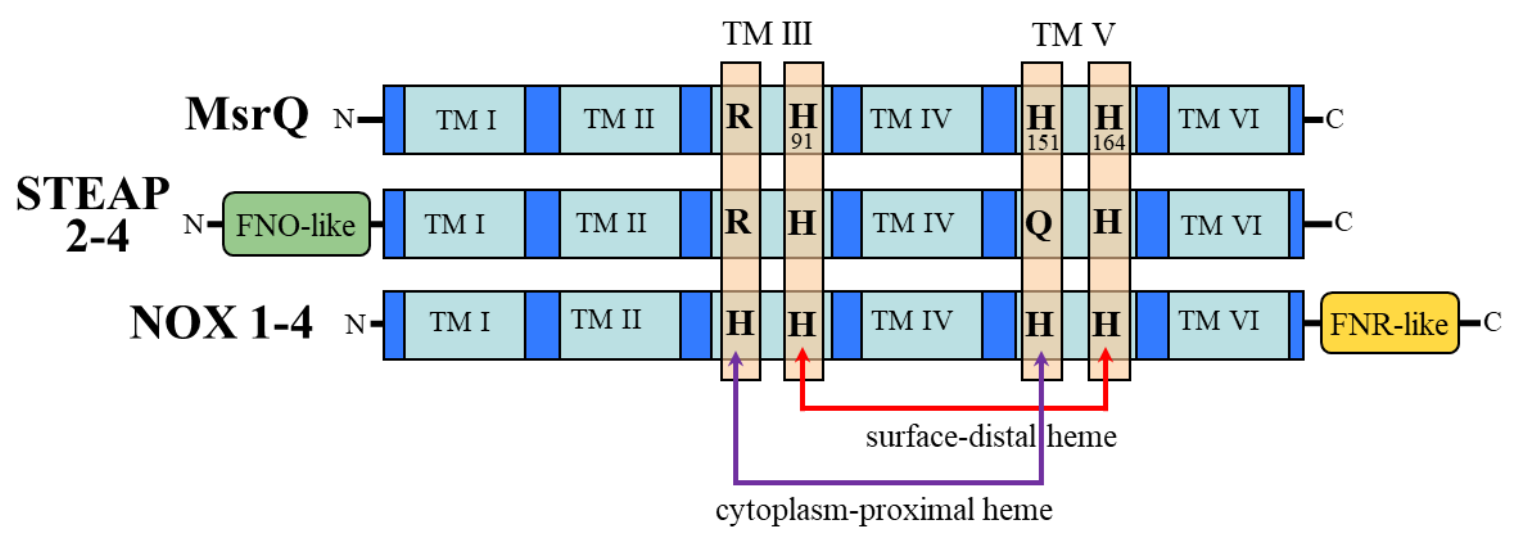

Figure 1. Scheme of the amino-acid sequences of the six transmembrane segments (TM) of representative proteins from the FRD domain superfamily, MsrQ, STEAP and NOX proteins. $^{21}$ STEAPs 2-3 and NOXs have an additional $\mathrm{N}$ - or C-terminal soluble dehydrogenase domain noted FNO-like (Pfam accession number PF00420) and FNR-like (PF00175), respectively. ${ }^{22}$ In most members of this superfamily, as illustrated here with NOXs, TM3 and TM5 contain the conserved two bis-histidine residue $(\mathrm{H})$ motifs, which are involved in the chelation of two b-type hemes. Red and violet arrows point the histidines that in NOXs bind the membrane surface-distal heme and the cytoplasm proximal-heme, respectively. In MsrQ and STEAP proteins, the first His is not conserved and is replaced by an Arg residue. In STEAP proteins, the third His is not conserved and is replaced by a Gln residue. ${ }^{21}$ For MsrQ, His residues are numbered according to the E.coli sequence.

The redox cofactors in MsrQ are expected to serve as an electronic relay between a cytosolic source of electrons and the periplasmic MsrP enzyme, allowing catalytic reduction of Met-SO into Met. Genetic approaches in E.coli suggested that the membrane quinone pool could be the electron donor to MsrQ. ${ }^{4}$ On the other hand, biochemical experiments proposed that the E. coli flavin reductase Fre could use NADH as a cytosolic source of electrons for MsrQ, by catalyzing heme reduction in the presence of free flavins. ${ }^{20}$

In this work, the cofactor content of MsrQ was re-investigated, using proteins solubilized in LMNG as a detergent and overexpressed from two different genetic constructions. Heme quantification together with EPR spectroscopy on the two purified MsrQ 
constructions, wild-type (WT) and H151A mutant, demonstrated that MsrQ holds a single btype heme cofactor, bis-histidine HALS type, located on the periplasmic side of the membrane. We further showed that MsrQ contains a FMN cofactor that presumably occupies the site where the second heme binds in other members of the FDR superfamily, on the cytosolic side of the membrane. In line with the presence of a FMN cofactor, the mechanism of reduction of MsrQ by the cytosolic flavin reductase Fre was investigated. Our data highlight an unprecedented mechanism by which Fre uses the internal FMN cofactor of MsrQ to catalyze electron transfer from cytosolic NADH to the heme located on the periplasmic side of the membrane, in the absence of free flavins.

\section{RESULTS}

Characterization of MsrQs solubilized with LMNG. Two different constructions encoding MsrQ were overexpressed in E.coli, solubilized from the membranes using Laury Maltose Neopentyl Glycol (LMNG) as a detergent and purified to homogeneity. The first construction encodes MsrQ fused at its C-terminal end to a His-tagged GFP protein, as described previously. ${ }^{20}$ After a first Ni-NTA column, the His-tagged GFP moiety was removed from MsrQ by cleavage with a TEV protease, followed by a second Ni-NTA column. An additional anion exchange chromatography was carried out to remove the residual GFP protein, which would otherwise contribute to the visible spectrum. This protein was referred as MsrQ. The second construction encodes for the MsrQ protein fused at its Cterminal end to a non-cleavable poly-His tag. This MsrQ form, termed MsrQ-Tag, was purified to homogeneity by a single Ni-NTA column.

The UV-visible spectra of both purified MsrQ forms were almost identical to that previously reported for MsrQ solubilized in Dodecyl $\beta$-D-maltoside (DDM) as detergent (Figure 2A and Supplementary Figure S1). ${ }^{20}$ The two MsrQ forms exhibited typical absorption peaks characteristic of the presence of oxidized b-type heme, with a Soret peak at $412 \mathrm{~nm}$ and broad $\alpha / \beta$ bands centered around $550 \mathrm{~nm}$ (Figure 2A and Supplementary Figure $\mathrm{S} 1)$. The Reinheitszahl values $\left(\mathrm{A}_{412 \mathrm{~nm}} / \mathrm{A}_{280 \mathrm{~nm}}\right.$ ratio) were similar for both proteins, varying from 0.9 to 1.0 from one preparation to another. Upon reduction with dithionite, reduced minus oxidized difference spectra of both MsrQ forms showed absorption peaks at 558, 528, and $426 \mathrm{~nm}$, corresponding to the $\alpha, \beta$, and Soret reduced heme bands, respectively (Figure 
2B and Supplementary Figure S1). The heme content of the MsrQ proteins was analyzed by the pyridine hemochromogen assay and the extinction coefficient values for the different heme absorption bands were reported in Table 1. For both MsrQ constructions, these values are similar. On note, these extinction coefficient values are about 2.5 times higher than those reported previously for MsrQ solubilized in DDM. ${ }^{20}$ Protein dosages carried out by the BCA and Lowry assays, or calculated from the MsrQ theoretical epsilon value at $280 \mathrm{~nm}$, show that for both MsrQ preparations, the heme/protein ratio is about 0.5 (Table 1). This suggests a substantial proportion of apoprotein form in the MsrQ preparations.

In a previous work, where DDM detergent was used for purification, it was reported that the MsrQ H151A mutation strongly impacts the MsrQ heme content, suggesting that His151 may be a heme ligand (Figure 1). ${ }^{20}$ Here, the purified H151A mutants of the two MsrQ constructions were overexpressed and purified to homogeneity, as reported above for the WT forms. While LMNG has replaced DDM in the purification process, the purified MsrQ H151A proteins exhibit similar extinction coefficient values for the heme Soret and $\alpha$ bands to those of the WT protein (Figure 2, Supplementary Figure S1, Table 1). These data suggest that His151 is not directly involved in heme coordination in MsrQ. Nevertheless, the significant lower Reinheitszahl values determined for the H151A mutant in both constructions compared to that of the WT protein (Table 1) suggest that the mutation induces a slight destabilization of the heme cofactor in MsrQ. Accordingly, the heme/protein ratio is lower for the H151A mutant compared to the WT (Table 1), in line with a larger amount of apoprotein form in the H151A mutant. 

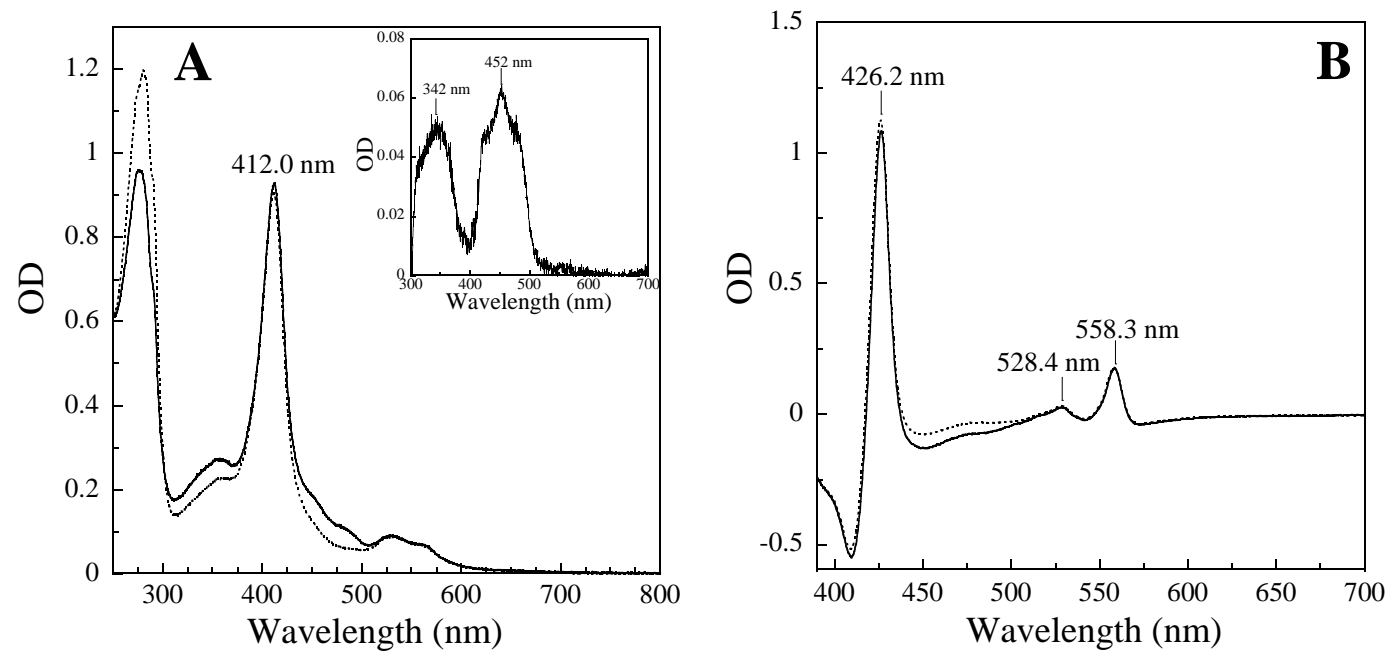

Figure 2. UV-visible spectral characterization of MsrQ WT and H151A forms at $7 \mu \mathrm{M}$ (heme concentration) in $50 \mathrm{mM}$ Tris- $\mathrm{HCl}, \mathrm{pH}$ 8.0; 0.004\% LMNG. A) Oxidized MsrQ WT (solid line) and MsrQ H151A (dashed line). The inset shows the difference spectrum MsrQ WT minus MsrQ H151A. B) Reduced-minus-oxidized difference spectra of MsrQ WT (solid line) and MsrQ H151A (dashed line). Reduced proteins were prepared by addition of sodium dithionite under anaerobic conditions.

Table 1. Extinction coefficient values of the Soret and $\alpha$ heme bands for the two purified MsrQ WT and H151A mutant forms

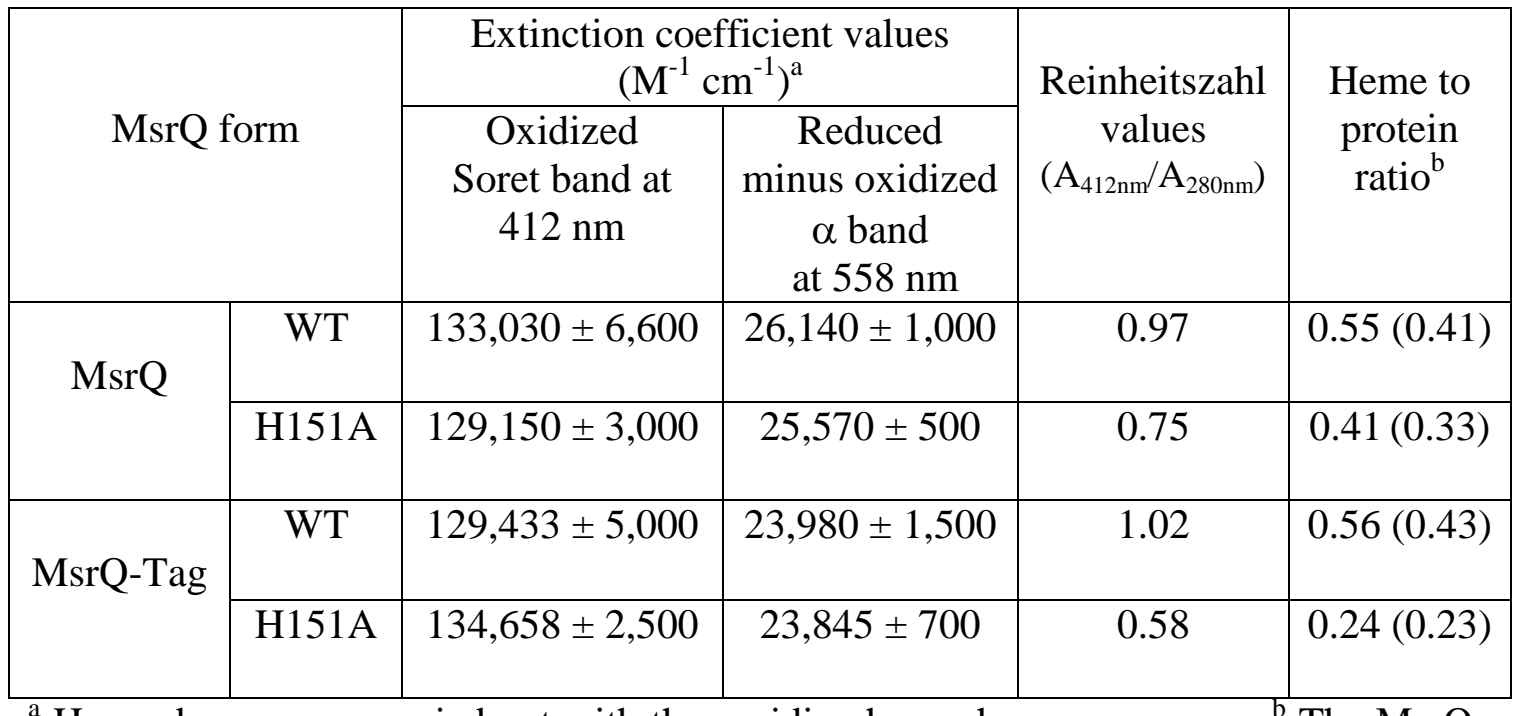

${ }^{a}$ Heme dosage was carried out with the pyridine hemochromogen assay. ${ }^{b}$ The MsrQ protein concentration was determined by the BCA and Lowry methods. In parenthesis, the protein concentration was calculated from the MsrQ theoretical epsilon value at $280 \mathrm{~nm} .^{26}$

FMN cofactor in MsrQ. Previous studies reported the presence of a bound flavin in MsrQ. ${ }^{27}$ The flavin content in our MsrQ preparations was investigated by HPLC. After 
thermal denaturation and centrifugation of the MsrQ solutions, HPLC analysis of the supernatant revealed the presence of a FMN cofactor in the MsrQ WT proteins (Figure 3b). No FAD nor riboflavin (Rf) were found in MsrQ (Figure 3b). Control experiments carried out on a $1 \mu \mathrm{M}$ MsrQ solution containing $1 \mu \mathrm{M}$ of commercial FAD or FMN showed that the added commercial flavin plus the MsrQ FMN cofactor were totally recovered after the thermal extraction and HPLC analysis (data not shown). Thus, no flavins hydrolysis nor photo-degradation processes occurred during the flavin analysis. Table 2 shows that MsrQ WT contains a stoichiometric amount of FMN with respect to the heme cofactor.

When the flavin content was investigated on the MsrQ H151A mutant, no flavin cofactors FAD, FMN nor riboflavin were identified (Figure 3c, Table 2). These data clearly show that the H151A mutation induces the loss of the FMN cofactor in MsrQ, whereas, as determined above (Table 1) the heme content was only slightly decreased in this mutant. Accordingly, the difference spectrum MsrQ WT minus MsrQ H151A shows absorbance bands in the 340-450 nm region, matching well with the presence of an oxidized flavin in the WT and not in the mutant (Inset of Figure 2A).



Figure 3. HPLC analysis of the flavin content of MsrQ WT and H151A mutant, prepared from the MsrQ-GFP fusion and TEV cleavage. The elution of the C18 column was followed at $266 \mathrm{~nm}$. Flavin and MsrQ solutions were heated at $96^{\circ} \mathrm{C}$ for $5 \mathrm{~min}$, centrifuged and $100 \mu \mathrm{l}$ of the supernatant was injected onto the C18 column. a) Commercial FAD, FMN and Rf, 1 $\mu \mathrm{M}$ each. FAD, FMN and Rf were eluted at 7.8, 10.1 and 14.7 minutes, respectively. b) MsrQ WT solution at $1 \mu \mathrm{M}$ (determined from the Soret absorption band at $412 \mathrm{~nm}$ ). The peak eluted at 10.2 min corresponds to a FMN molecule at a concentration of $0.85 \mu \mathrm{M}$. c) MsrQ H151A solution at $3 \mu \mathrm{M}$ (determined from the Soret absorption band at $412 \mathrm{~nm}$ ). No peak associated to a flavin was detected in this mutant. 
Table 2. Stoichiometry FMN/heme cofactors in MsrQ

\begin{tabular}{|c|c|c|}
\hline \multicolumn{2}{|c|}{ MsrQ form } & Ratio FMN $^{\mathrm{a}} /$ heme $^{\mathrm{b}}$ \\
\hline \multirow{2}{*}{ MsrQ } & WT & $0.90 \pm 0.05$ \\
\cline { 2 - 3 } & H151A & No flavin detected \\
\hline MsrQ-Tag & WT & $0.82 \pm 0.03$ \\
\cline { 2 - 3 } & H151A & No flavin detected \\
\hline
\end{tabular}

${ }^{a}$ The FMN concentration in MsrQ was determined by HPLC analysis (Figure 3). For each MsrQ form, the FMN content was determined from three independent measurements. ${ }^{b}$ The heme concentrations of the MsrQ solutions were determined using the extinction coefficient values of Table 1.

Electronic Paramagnetic Resonance on MsrQ. In order to further characterize the heme cofactor in MsrQ, EPR spectroscopy was carried out on the oxidized MsrQ WT and H151A mutant forms. A first study was performed on the MsrQ-Tag WT protein, for which the good purification yield allowed the preparation of concentrated solution (302 $\mu \mathrm{M}$, Figure 4a). As shown in Figure 4a, the spectrum exhibits noticeable signatures attesting for the presence of two different low-spin ferric hemes. A conventional low-spin heme is observed with a well-resolved rhombic signal at $g_{z}=2.95, g_{y}=2.25, g_{x}=1.5 .{ }^{28}$ The $\mathrm{g}=3.62$ signal could be attributed to the large $\mathrm{g}_{\mathrm{z}}$ of a highly-anisotropic low-spin (HALS) type signal of a heme species. ${ }^{28,29}$ These two low-spin signatures can be associated with btype hemes, where the $\mathrm{Fe}^{3+}$ ion is coordinated by two axial histidine ligands (bis-His). It is well established that in low-spin hemes with axial bis-histidine coordination, the anisotropy of the g-tensor is closely related to the dihedral angle between the imidazole planes of the two histidine ligands. ${ }^{28,29}$ Such a magneto-structural correlation could be rationalized in the frame of the Griffith's $t_{2 g}$ hole model enabling the $g$ values to be expressed as a function of parameters characterizing the ligand field experienced by the $\mathrm{Fe}^{3+}$ ion ${ }^{30,31}$ and was confirmed by EPR experiments performed on single crystal of multihemic cytochrome. ${ }^{32,33}$ These lowspin signals likely reflect the presence of different orientations for the two axial histidine heme ligand planes with respect to each other, the rhombic signal being associated with roughly parallel histidine planes, whereas the HALS one describes nearly perpendicular axial 
histidine ligand planes. ${ }^{28,29}$ Others EPR signals are also observable in Figure 4a. The $g=5.8$ signal, with a shoulder at $g=6.54$, is characteristic of a high-spin penta-coordinated heme. ${ }^{34}$ Nevertheless, despite its marked amplitude, it presumably represents only a small heme amount in MsrQ. ${ }^{34,35}$ Finally, the $\mathrm{g}=4.3$ signal is typical for non-specific $\mathrm{Fe}^{3+}$ ion bound to

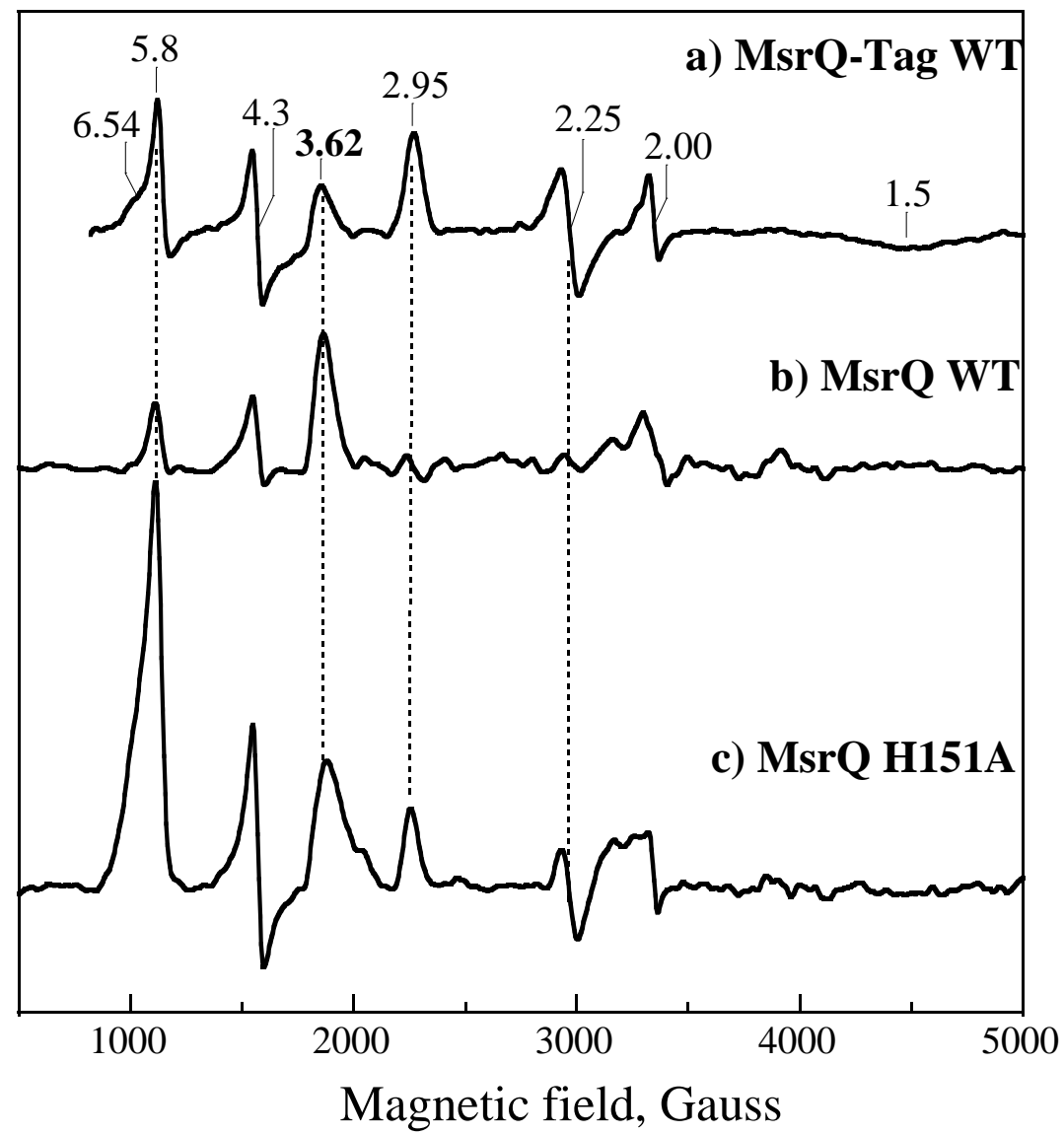

the protein and the $\mathrm{g}=2.00$ signal reveals the presence of organic radical species in the protein solution.

Figure 4. X-band EPR spectra of the ferric MsrQ WT and H151A mutant, in $50 \mathrm{mM}$ Tris$\mathrm{HCl}$ pH 7.6, LMNG 0.004\%. a) MsrQ-Tag WT form, $302 \mu \mathrm{M}$. b) MsrQ WT form, $162 \mu \mathrm{M}$. c) MsrQ H151A mutant form, $171 \mu \mathrm{M}$. The MsrQ concentrations were determined using the extinction coefficient values of Table 1 . Experimental conditions: $15 \mathrm{~K}$; microwave power $=2$ $\mathrm{mW}$; microwave frequency a) $9.48 \mathrm{GHz}$, b) $9.36 \mathrm{GHz}$, c) $9.37 \mathrm{GHz}$; modulation frequency = $100 \mathrm{kHz}$; modulation amplitude $=20 \mathrm{G}$. The spectra were obtained as the average of ten scans and result from subtraction with the signal of the buffer. In a), the $g$ values are labelled for each signal.

Due to the presence of several paramagnetic species in the spectrum of MsrQ-Tag WT, the quantification of each species is not a straightforward task. In the first step, the spin intensity of the low-spin heme signal was determined by double integration between 200 and 
$500 \mathrm{mT}$ of the EPR spectrum recorded at $15 \mathrm{~K}$ under non-saturating conditions and by comparison with a $1 \mathrm{mM} \mathrm{Cu}^{2+}$-EDTA standard. This double integration was also compared to that of the low-spin heme signal given by an equine heart myoglobin-azide complex sample, which enabled to estimate the uncertainty on this determination at about $10 \%$ (Table 3 ). In a second step, as only the $\mathrm{g}_{\mathrm{Z}}=3.62$ peak of the HALS heme signal can be observed on the experimental spectrum, the other two g-values were estimated by using the Griffith's model of low-spin ferric hemoproteins to be close to $g=1.53$ and 0.43 , respectively. ${ }^{30,31}$ This enabled to simulate the EPR spectrum of the HALS heme and to calculate the proportionality factor between double integration of the spectrum and the surface under the positive peak at low field corresponding to the highest g-value. This factor was found to be close to $10^{3}$ and not very sensitive to the linewidth description and g-values $( \pm 10 \%)$. Then, by integrating the $\mathrm{g}=3.62$ peak of the HALS heme signal and using this proportionality factor, the spin intensity of the HALS heme could be determined with a reasonable accuracy (Table 3). For the high-spin heme signal, the signal was taken at low temperature $(5 \mathrm{~K})$ to account for nonCurie behavior of the EPR intensity and compared to that given in the same conditions by a met-myoglobin reference sample using the method previously described. ${ }^{35}$ The intensity of the $\mathrm{g}=4.3$ signal arising from adventitious ferric ions was evaluated by comparison with a sample of $\mathrm{Fe}^{3+}$-EDTA complex (Table 3). Finally, the organic radical signal, which is strongly saturated at $15 \mathrm{~K}$, was also recorded at higher temperature $(60 \mathrm{~K})$ in non-saturating conditions and its spin-intensity was evaluated at about $1 \mu \mathrm{M}$. This signal was also studied at higher microwave frequency (Q-band), showing a nearly axial g-tensor with $\mathrm{g} \perp=2.005$ and

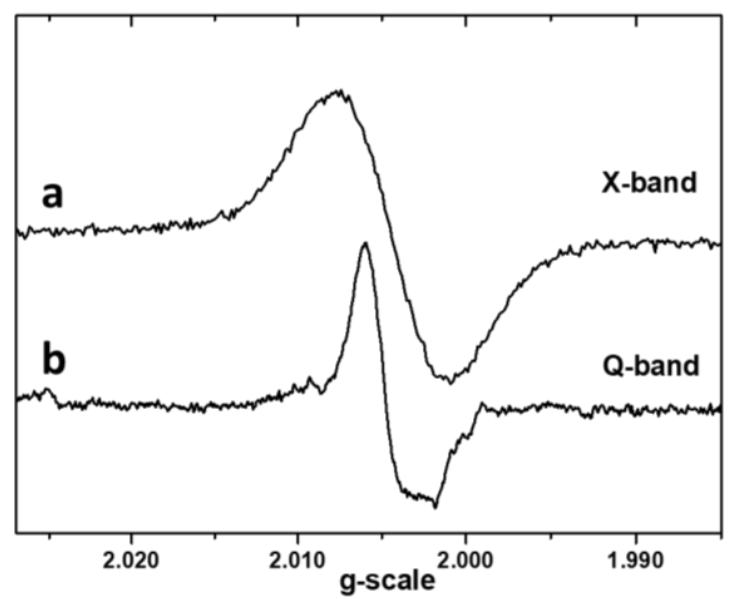

$\mathrm{g}_{/ /}=2.002$ (Figure 5). These g-values and the large peak-to-peak linewidth in X-band ( 1.2 $\mathrm{mT}$ ) are typical of a flavin semiquinone radical, ${ }^{36,37}$ which agrees well with the presence of a FMN cofactor in the protein. 
Figure 5. X-band (a) and Q-band (b) EPR spectra showing the radical signal of the MsrQ-Tag WT protein preparation. Experimental conditions: $60 \mathrm{~K}$; microwave frequency a) 9.4806 $\mathrm{GHz}$, b) $34.098 \mathrm{GHz}$; microwave power a) $0.2 \mathrm{~mW}$, b) $0.1 \mathrm{~mW}$; modulation amplitude $1 \mathrm{mT}$ at $100 \mathrm{kHz}$; averaged scans a) 10, b) 35 . The baseline of the resonant cavity was subtracted from the Q-band spectrum.

The MsrQ WT form, purified after a TEV cleavage of the MsrQ-GFP fusion, was also investigated by EPR. As shown in Figure 4b, whereas the high-spin $(\mathrm{g}=5.8)$ and HALS (g = 3.62) heme signals are also present in this MsrQ form, the low-spin rhombic heme signature $\left(\mathrm{g}_{\mathrm{z}}=2.95, \mathrm{~g}_{\mathrm{y}}=2.25\right.$ and $\left.\mathrm{g}_{\mathrm{x}}=1.50\right)$ almost totally disappeared compared to MsrQ-Tag (Figure 4a). Quantification of the heme signals using the data set up for MsrQ-Tag WT (Figure 4a, Table 3) shows that in this preparation about $98 \%$ of the hemes are in a low-spin HALS hexa-coordinated bis-histidine form, whereas the high-spin penta-coordinated heme represents only about $1 \%$ of the total heme content in MsrQ (Table 3).

The EPR spectrum of the MsrQ H151A mutant (Figure 4c), purified after a TEV cleavage of the MsrQ H151A-GFP fusion, exhibits signatures for the presence of a pentacoordinated high-spin heme $(\mathrm{g}=5.8)$, a low-spin HALS hexa-coordinated bis-histidine heme ( $\mathrm{g}=3.62)$ and a low-spin rhombic hexa-coordinated bis-histidine heme, with $\mathrm{g}_{\mathrm{z}}=2.95, \mathrm{~g}_{\mathrm{y}}=$ 2.25 and presumably $\mathrm{g}_{\mathrm{z}}$ at 1.5 . Quantification of the different heme signals on the H151A mutant spectrum showed that the low-spin hexa-coordinated HALS heme accounts for about $93 \%$ of the total heme content, whereas the two other forms were found minors, with about $5 \%$ for the high-spin penta-coordinated heme and $2 \%$ for the rhombic low-spin hexacoordinated heme (Table 3). On note, the weak signal visible around $g=2.0$ on the H151A mutant spectrum is mainly due to a $\mathrm{Cu}$ (II) signal contribution arising from the cavity.

Table 3. Quantification of the EPR signatures shown in Figure 4

\begin{tabular}{|c|c|c|c|c|c|c|}
\hline EPR spectrum & $\begin{array}{c}\text { low-spin } \\
\text { heme }^{\mathrm{a}} \\
(\mathrm{g}=2.95)\end{array}$ & $\begin{array}{c}\text { HALS } \\
\text { heme }^{\mathrm{a}} \\
(\mathrm{g}=3.62)\end{array}$ & $\begin{array}{c}\text { high-spin } \\
\text { heme }^{\mathrm{a}} \\
(\mathrm{g}=5.8)\end{array}$ & $\begin{array}{c}\text { non } \\
\text { specific Fe } \\
(\mathrm{g}=4.3)\end{array}$ & $\begin{array}{l}\text { total heminic } \\
\text { EPR signal }^{\mathrm{a}}\end{array}$ & $\begin{array}{c}\text { total } \\
\text { heme } \\
\text { protein }^{b}\end{array}$ \\
\hline $\begin{array}{c}\text { a) MsrQ-Tag } \\
\text { WT }\end{array}$ & $\begin{array}{c}50 \mu \mathrm{M} \\
16 \%\end{array}$ & $\begin{array}{c}250 \mu \mathrm{M} \\
83 \%\end{array}$ & $\begin{array}{c}5 \mu \mathrm{M} \\
1 \%\end{array}$ & $10 \mu \mathrm{M}$ & $\begin{array}{c}305 \mu \mathrm{M} \\
100 \%\end{array}$ & $302 \mu \mathrm{M}$ \\
\hline b) MsrQ WT & $\sim 1.5 \%$ & $\sim 98 \%$ & $\sim 0.5 \%$ & present & $100 \%$ & $162 \mu \mathrm{M}$ \\
\hline c) MsrQ H151A & $\sim 5 \%$ & $\sim 93 \%$ & $\sim 2 \%$ & present & $100 \%$ & $170 \mu \mathrm{M}$ \\
\hline
\end{tabular}

${ }^{\mathrm{a}}$ The $\%$ value indicated the $\%$ of the total heme content detected by EPR. ${ }^{\mathrm{b}}$ The total heme protein was determined from the absorbance of the oxidized Soret band, using the extinction coefficient values reported in Table 1. 
Altogether, these data indicate that MsrQ mostly contains a low-spin b-type heme, hexa-coordinated by two histidine axial ligands, predominantly present in a HALS form where the two histidine axial ligand planes are perpendicular to each other. The MsrQ-Tag form is slightly more heterogeneous, with in addition to the low-spin HALS form, the presence of a small proportion of low-spin rhombic heme where the two histidine axial ligand planes are parallel to each other. The H151A mutation does not notably affect the properties of the heme in MsrQ, with still the presence of the predominant low-spin hexa-coordinated HALS heme form in this mutant (Table 3).

Reduction of MsrQ by Fre without free flavins. Previous work showed that the E.coli flavin reductase Fre catalyzes the reduction of MsrQ heme in the presence of free FMN and NADH as electron donor. ${ }^{20}$ Fre does not use flavin as cofactor but as substrate, which after reduction by NADH in its the active site, is released in the solvent. ${ }^{38}$ These previous results agree with the fact that the MsrQ hemes can be reduced by the free FMN hydroquinone form generated by Fre activity. ${ }^{20}$

Since we evidenced here the presence of a FMN molecule in MsrQ, we tested whether Fre could reduce MsrQ in the absence of free flavins. The reaction was carried out in a glove box under nitrogen atmosphere in order to prevent any $\mathrm{O}_{2}$-dependent $\mathrm{MsrQ}$ reoxydation. As shown in Figure 6A, in the presence of NADH as electron donor and in the absence of free flavins, catalytical amount of Fre fully reduces the MsrQ heme. This is clear from the spectrum of MsrQ, which after $15 \mathrm{~min}$ incubation time in these conditions exhibits characteristic features for a fully reduced heme (Figure 6A). The reaction kinetic, followed at $558 \mathrm{~nm}$ for the apparition of the $\alpha$ band of the reduced heme, is linear during the first minutes. No reduction of MsrQ was observed in the absence of Fre and in the presence of NADH, or in the absence of NADH (Figure 6A). Interestingly, initial velocities for MsrQ heme reduction followed a saturated hyperbolic dependence on MsrQ concentrations. This indicates a Michaelis-type behavior for Fre when using oxidized MsrQ as a substrate (Figure 6B). An apparent Michaelis constant $K_{m}$ of $2.6 \pm 0.2 \mu \mathrm{M}$ and a maximal velocity ( $k_{\text {cat }}$ ) of $3.8 \pm 0.1 \mathrm{~s}^{-1}$ for the reduction of MsrQ catalyzed by Fre was calculated (Table 4). Rather surprisingly, these $K_{m}$ and $k_{\text {cat }}$ values are in the same order of magnitude than that determined for the reduction of free FMN catalyzed by Fre in the presence of NADH. ${ }^{39}$ This shows that the catalysis of the reduction of MsrQ by Fre in the absence of free flavins is very efficient. 
As shown in Table $4, K_{\mathrm{m}}$ and $k_{\text {cat }}$ values determined for the reduction of MsrQ WT by Fre are only slightly affected by the presence of extensions on the C-terminus part of MsrQ, His-tag or GFP fusion. These data suggest that formation of the Fre-MsrQ Michaelis complex during catalysis does not involve the C-terminal part of MsrQ.


Figure 6. Reduction of MsrQ WT by NADH catalyzed by Fre in the absence of free flavins, at $20^{\circ} \mathrm{C}$ under anaerobiosis. A) ( ) Absorption spectrum of oxidized MsrQ WT at $3.1 \mu \mathrm{M}$ in $50 \mathrm{mM}$ Tris/HCl buffer, $\mathrm{pH}$ 7.6, 0.016\% LMNG and $250 \mu \mathrm{M}$ NADH. $(\diamond)$ Same solution after addition of $0.017 \mu \mathrm{M}$ of Fre and $15 \mathrm{~min}$ incubation time. The inset shows the corresponding kinetic trace of MsrQ WT reduction at $558 \mathrm{~nm}$ before and after addition of Fre. B) Dependence of the initial velocity of MrsQ WT reduction catalyzed by Fre to MsrQ concentrations. Initial velocities were determined from the increase of the absorbance at 558 $\mathrm{nm}$, immediately after the addition of $0.017 \mu \mathrm{M}$ of Fre in the spectrophotometric cuvette containing $50 \mathrm{mM}$ Tris/HCl buffer, $\mathrm{pH} \mathrm{7.6,0.016 \%} \mathrm{LMNG,} 250 \mu \mathrm{M}$ NADH and various concentrations of oxidized MsrQ-Tag WT. The solid line is the best fit to a Michaelis-Menten equation, with a $K_{m}$ value of $2.6 \pm 0.2 \mu \mathrm{M}$ and a $\mathrm{V}_{\max }$ value of $0.0083 \pm 0.0002 \mathrm{OD}_{558 \mathrm{~nm}} \cdot \mathrm{mn}^{-1}$ $\left(k_{\mathrm{cat}}=3.8 \mathrm{~s}^{-1}\right)$.

Table 4. Kinetic parameters for the reduction of MsrQs or free FMN catalyzed by Fre in the presence of NADH as electron donor. The reactions were carried out under anaerobiosis at $20^{\circ} \mathrm{C}$ in the same conditions than those described in Figure 6

\begin{tabular}{|c|c|c|c|}
\hline \multicolumn{2}{|c|}{ Substrate $^{\mathrm{a}, \mathrm{b}}$} & $K_{m}(\mu \mathrm{M})$ & $k_{\text {cat }}\left(\mathrm{s}^{-1}\right)$ \\
\hline \multirow[t]{2}{*}{ MsrQ } & $\mathrm{WT}^{\mathrm{c}}$ & $2.6 \pm 0.2$ & $3.8 \pm 0.1$ \\
\hline & $\mathrm{H} 151 \mathrm{~A}^{\mathrm{d}}$ & I & trace of activity \\
\hline \multirow[t]{2}{*}{ MsrQ-Tag } & $\mathrm{WT}^{\mathrm{e}}$ & $10.3 \pm 1.5$ & $1.5 \pm 0.1$ \\
\hline & $\mathrm{H} 151 \mathrm{~A}^{\mathrm{d}}$ & I & 0 \\
\hline MsrQ-GFP & $\mathrm{WT}^{\mathrm{e}}$ & $7.9 \pm 1.0$ & $4.4 \pm 0.2$ \\
\hline \multicolumn{2}{|c|}{ FMN } & $0.8^{f}$ & $4.1^{\mathrm{f}}$ \\
\hline
\end{tabular}

${ }^{\mathrm{a}}$ The reactions were carried out in $50 \mathrm{mM}$ Tris/HCl pH 7.6, LMNG $0.004 \%$ and NADH 250 $\mu \mathrm{M} .{ }^{\mathrm{b}}$ The reduction of MsrQ was followed at $558 \mathrm{~nm} .{ }^{\mathrm{c}}$ MsrQ concentrations were varied 
from 0.5 to $30 \mu \mathrm{M} .{ }^{\mathrm{d}}$ MsrQ H151A concentration was $30 \mu \mathrm{M} .{ }^{\mathrm{e}}$ MsrQ-GFP concentrations were varied from 1.5 to $80 \mu \mathrm{M}$. ${ }^{\text {f }}$ From reference ${ }^{39}$.

The MsrQ H151A mutant, which is devoid of flavin cofactor (Table 2), was tested for reduction by Fre in the presence of $\mathrm{NADH}$, without addition of free flavins (Figure 7). Whereas in the presence of $5 \mu \mathrm{M}$ of MsrQ H151A, no reduction was observed (Figure 7A), with $19 \mu \mathrm{M}$ of MsrQ H151A, only a slight reduction of the heme occurred (Figure 7B). From the kinetic traces recorded at $558 \mathrm{~nm}$ in the presence of $0.031 \mu \mathrm{M}$ of Fre (Figure 7B), a rate of $0.07 \mathrm{~s}^{-1}$ for the MsrQ H151A heme reduction by Fre was calculated. This rate is less than $2 \%$ of the value calculated for the MsrQ WT in the conditions of the inset of Figure 6, where MsrQ and Fre concentrations are about two times less than those of Figure 7B. Addition of free FMN in the reaction mixture induced a fast and complete reduction of the heme of the MsrQ H151A mutant (Figure 7B), showing that the H151A mutation does not impair the ability of the heme to be reduced by flavins. These data fully support the fact that the reduction of the MsrQ heme by Fre in the absence of free flavins occurs thanks to the MsrQ FMN cofactor. The residual reduction of MsrQ H151A by Fre as observed in Figure 7B might be associated with the presence of a trace amount of FMN in the mutant.

Altogether, these data demonstrate that Fre uses the FMN MsrQ cofactor as a substrate to catalyze the reduction of the MsrQ heme in the presence of NADH as electron donor. Since the Fre active site was described to bind both the flavin and the NADH close together to favor an hydride transfer, ${ }^{38,40}$ our present data suggest an unprecedented mechanism by which the MsrQ FMN cofactor could be share between the MsrQ and Fre active sites. 

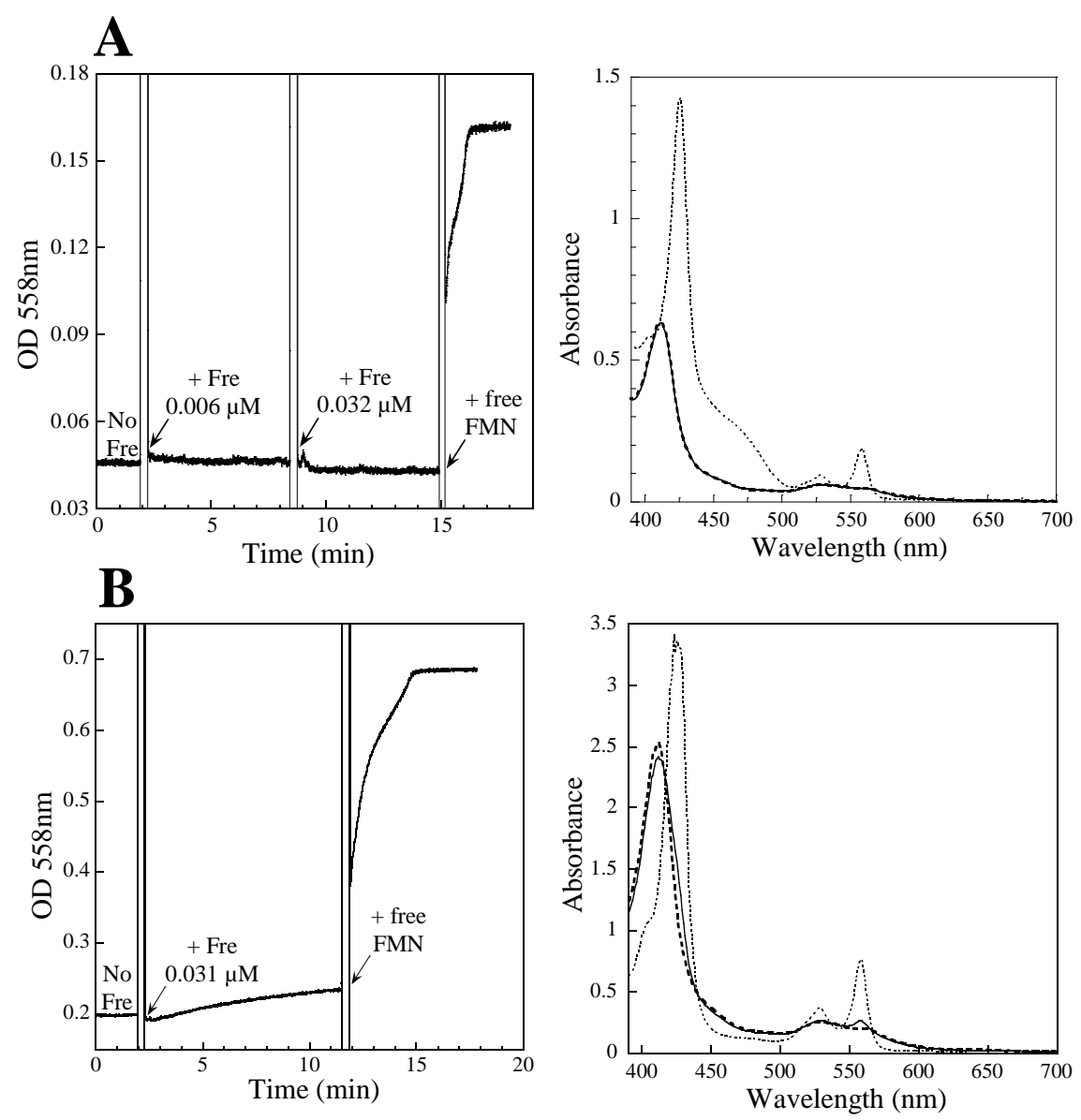

Figure 7. Reduction of MsrQ H151A mutant by NADH catalyzed by Fre in the absence and in the presence of free flavins, at $20^{\circ} \mathrm{C}$ under anaerobiosis. A) left panel. MsrQ $\mathrm{H} 151 \mathrm{~A}$ at 5 $\mu \mathrm{M}$ in $50 \mathrm{mM}$ Tris/HCl buffer, $\mathrm{pH} 7.6,0.004 \% \mathrm{LMNG}$ and $250 \mu \mathrm{M} \mathrm{NADH}$. The kinetic of MsrQ H151A reduction was followed at $558 \mathrm{~nm}$, without addition of Fre and with the subsequent addition of $0.006 \mu \mathrm{M}$ and $0.032 \mu \mathrm{M}$ Fre and finally $94 \mu \mathrm{M}$ of free FMN, as noted on the figure. Right panel. Absorption spectra of the reaction mixture without addition of Fre (bold dashed line), after addition of Fre at 15 min reaction time (thin line), and after addition of free FMN at 17 min reaction time (thin dashed line). B) left panel. MsrQ H151A at 19.4 $\mu \mathrm{M}$ in $50 \mathrm{mM}$ Tris/HCl buffer, $\mathrm{pH} 7.6,0.004 \% \mathrm{LMNG}$ and $250 \mu \mathrm{M} \mathrm{NADH}$. The kinetic of MsrQ H151A reduction was followed at $558 \mathrm{~nm}$, without addition of Fre, and with the subsequent addition of $0.031 \mu \mathrm{M}$ Fre and finally $41 \mu \mathrm{M}$ of free FMN, as noted on the figure. Right panel. Absorption spectra of the reaction mixture without addition of Fre (bold dashed line), after addition of Fre at 11 min reaction time (thin line), and after addition of free FMN at 17 min reaction time (thin dashed line). 
Interaction between Fre and MsrQ H151A. Previous work showed that Fre forms a specific complex with MsrQ WT. ${ }^{20}$ To investigate if the FMN cofactor of MsrQ could be involved in this interaction, formation of the complex between Fre and MsrQ H151A mutant was studied using surface plasmon resonance analysis. The affinity of MsrQ WT and H151A mutant for Fre was estimated using a surface functionalized with Fre by amine coupling. As shown in Figure 8A, a specific interaction between Fre and MsrQ H151A mutant was observed in a concentration dependent manner, similarly to that observed between Fre and MsrQ WT (Figure 8B and ref. ${ }^{20}$ ). Using a steady state affinity model for analysis, apparent $\mathrm{K}_{d}$ values of $18.8 \pm 1.0 \mu \mathrm{M}$ for the MsrQ H151A mutant/Fre complex and $32.7 \pm 0.9$ $\mu \mathrm{M}$ for the MsrQ WT/Fre complex were determined (Figure 8C). These results show that the H151A mutation has no significant quantitative effects on the MsrQ/Fre interaction. Since the MsrQ H151A mutation specifically induces the loss of the FMN cofactor, these data suggest that the flavin cofactor is not involved in the formation of the MsrQ/Fre complex.
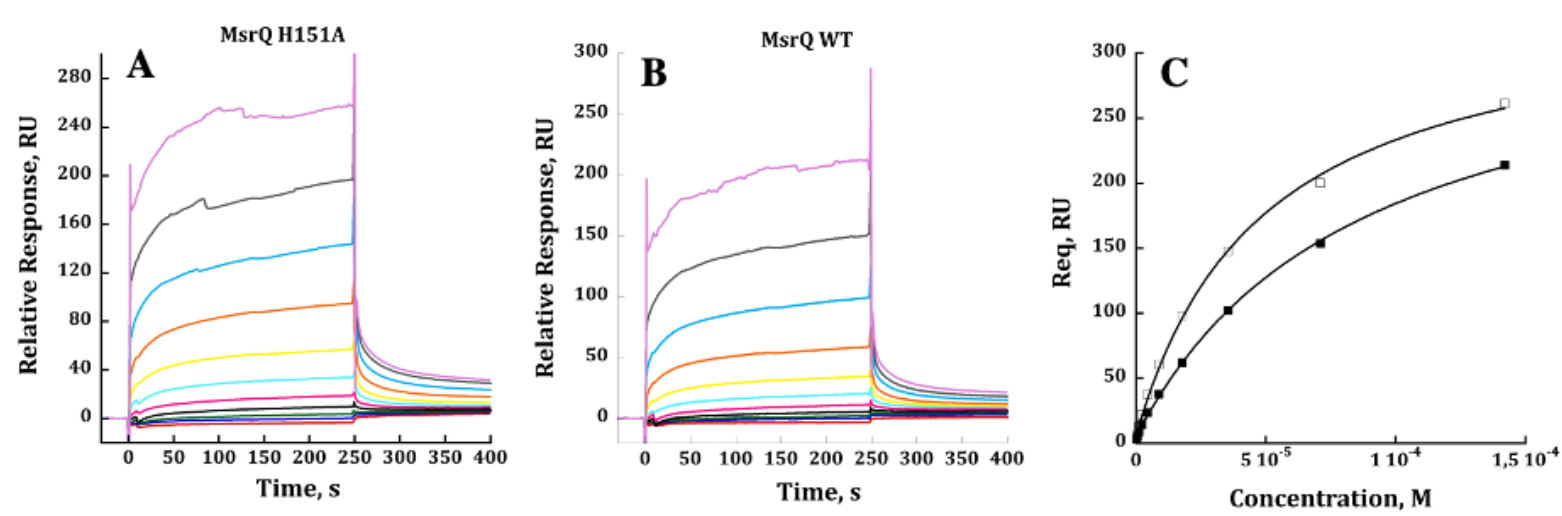

Figure 8. Surface plasmon resonance analysis of MsrQ WT and MsrQ H151A mutant binding to immobilized Fre. A) The purified MsrQ H151A mutant or B) MsrQ WT proteins (both produced from the MsrQ-GFP fusion with TEV cleavage) were injected over a Fre functionalized surface at a flow rate of $20 \mu \mathrm{L} / \mathrm{min}$ in the running buffer containing $50 \mathrm{mM}$ Tris- $\mathrm{HCl} \mathrm{pH} \mathrm{8.0,} 150 \mathrm{mM} \mathrm{NaCl}, 0.004 \%$ LMNG and $0.05 \%$ Tween 20. The sensorgrams were obtained for a range of MsrQs concentrations, from the bottom to the top, at $0,0.10$, $0.22,0.44,0.88,1.77,3.54,7.10,14.20,28.40$ and $56.80 \mu \mathrm{M}$. C) Steady state affinity model analysis of the MsrQ WT/Fre (black square) and MsrQ H151A/Fre (white square) interactions, assuming a stoichiometric ratio MsrQ/Fre complex of 1 . $\mathrm{K}_{d}$ values of $18.8 \pm 1.0$ $\mu \mathrm{M}$ and $32.7 \pm 0.9 \mu \mathrm{M}$ for the MsrQ H151A /Fre and MsrQ WT/Fre complexes were calculated, respectively. 


\section{DISCUSSION}

MsrQ, which belongs to the heme-containing transmembrane ferric reductase FRD superfamily, ${ }^{21}$ has been characterized as the specific electron donor of $\mathrm{MsrP}^{4}$ a new type of periplasmic methionine sulfoxide reductase involved in the repair of $\mathrm{HOCl}$ oxidized methionine residues. ${ }^{4,5}$ Previous investigations suggested that the cytosolic flavin reductase Fre is the initial electron source of the MsrPQ system, by catalyzing MsrQ heme reduction in the presence of free flavins and $\mathrm{NADH}^{20}$ In this work, we have provided a further characterization of the MsrQ cofactors and the mechanism of their reduction by Fre. MsrQ is a flavo-hemo protein, where its FMN cofactor plays a central role in heme reduction. This work highlights an unprecedented electron transfer mechanism between Fre and MsrQ, where the FMN cofactor could shuttle between its MsrQ binding site nearby the b-type heme and the active site of Fre, where it gets directly reduced by NADH.

Representative members of the heme-containing transmembrane FRD superfamily, such as the eukaryotic NADPH oxidases NOXs, bind two b-type hemes in their transmembrane domain from two pairs of conserved His residues. ${ }^{21,23}$ However in MsrQ, only one pair of His is conserved, His91 and His164, suggesting the presence of a b-type heme positioned toward the extracellular side of the membrane (Figure 1). For the second His pair, which in NOXs binds another b-type heme located on the cytosolic side of the membrane, ${ }^{23}$ in MsrQ one His is not conserved and replaced by an Arg. ${ }^{21}$ Thus, if MsrQ binds a second heme in that position using the remaining histidine His151, one would expected a pentacoordination with His151 as the sole axial ligand, the Arg residue been too basic to be considered as a potential ligand.

In this work, heme dosages in MsrQ revealed that the H151A mutation does not affect its heme content (Table 1). This suggests that, contrary to what was proposed previously, ${ }^{20}$ His151 is not involved in heme coordination in MsrQ. Furthermore, EPR studies showed that MsrQ WT and its H151A mutant mainly contain only one type of heme (Table 3), a low-spin HALS hexa-coordinated bis-histidine one, where the two axial His ligand planes are nearly perpendicular to each other. Two other minor heme forms were detected by EPR in MsrQ (Table 3), and could most likely result from an alteration of the HALS heme. A high-spin penta-coordinated form, accounting for only a very few percent of the total heme content (Table 3), could result from the loss of one His axial ligand. The noticeably more detected 
rhombic low-spin hexa-coordinated heme, whose proportion varies among MsrQ preparations (Table 3), differs from the HALS form by having its two axial histidine ligand planes roughly parallel to each other. ${ }^{29}$ It could result from the rotation of a His side chain. The presence of these different heme forms in the MsrQ preparations might reflect some flexibility in the surrounding of the His ligands, allowing slight motions of these ligands versus the heminic iron atom.

Altogether, our data on two different MsrQ forms (His-tagged and TEV cleaved), both on the WT and the H151A mutant, demonstrate that MsrQ accommodates a single heme per polypeptide chain, HALS type, hexa-coordinated bis-histidine and located on the periplasmic side of the membrane. These results revise our previous proposition, which based on heme and polypeptide concentration assays, suggested the presence of two hemes on MsrQ. ${ }^{20}$ Potential experimental errors, which nevertheless we were not able to trace a posteriori, could account for these previous data. Moreover, this discrepancy was previously misleadingly sustained by the Soret-band signal loss upon His151 mutations while using DDM as detergent. $^{20}$ This artifact is now strongly limited using the new purification procedure described here, where LMNG replaces DDM.

We further confirm the presence of a FMN cofactor in MsrQ, as previously mentioned, ${ }^{27}$ with a 1 to 1 stoichiometry with respect to the heme (Table 2). No evidence for the presence of FAD was found in MsrQ. Interestingly, the H151A mutation specifically leads to the loss of the FMN cofactor (Table 2), without affecting the heme properties, as characterized by UV-visible and EPR spectroscopies (see above and Tables 1 and 3). These data strongly suggest that His151 is located close to the FMN binding site and might be involved in stabilizing interactions with the flavin cofactor. Since His151 aligns with one of the two histidines that bind the second heme in NOXs and other representatives of the FRD superfamily (Figure 1), ${ }^{21}$ our data suggest that the second heme of NOXs is replaced by a flavin cofactor in MsrQ.

The eukaryotic STEAP proteins (six-transmembrane epithelial antigen of prostate), which also belong to the heme-containing transmembrane FRD superfamily, are phylogenetically related to MsrQ in that their sequences exhibit only one bis-histidine motif that can potentially bind a single heme (Figure 1). This is clearly illustrated by the recent cryo-electron microscopy structures of STEAP1 and STEAP4 proteins solved at 3.0-3.8 resolution, which showed a single b-type bis-histidine heme in the transmembrane domain and pointing towards the extracellular space. ${ }^{24,25,41}$ Notably, on the intracellular side of the transmembrane domain, both STEAP1 and STEAP4 structures showed an electron density 
fitting well with a FAD molecule. Superimposition of the 3D structures of the transmembrane domains of STEAP4 and CsNOX, a cyanobacterial analog of NOX5, reveals that they share a same topology and coordination of the heme present on the extracellular side of the membrane. ${ }^{41}$ In addition, the FAD isoalloxazine ring in STEAPs binds in a same position than the second heme in NOX5. ${ }^{23,41}$ Our data suggest that a similar heme and flavin topology is present in MsrQ, with however a FMN instead a FAD cofactor. The MsrQ His151 residue, showed to be associated with the FMN binding site, is not conserved in STEAPs and is replaced by a Gln residue. ${ }^{21}$ Interestingly, in the STEAP4 structure, this Gln is close to the isoalloxazine ring of the FAD, its peptidyl carbonyl group being potentially to a $\mathrm{H}$-bond distance of the 2 'OH ribityl moiety of the flavin. ${ }^{25}$ It is therefore possible that in MsrQ the peptidyl carbonyl group of H151 also interacts with the ribityl chain of the FMN (Figure 9B). Thus, the H151A mutation, by modifying the local conformation of the His151 peptide chain, could destabilize this interaction, leading, as observed in this work, to the loss of the FMN cofactor.

Altogether, these data demonstrate that MsrQ is a membrane bound-flavocytochrome with a topology of its cofactors similar to that described for the FRD domain of STEAP proteins, with a b-type heme on the periplasmic side of the membrane and a tightly bound FMN cofactor on the cytosolic side of the membrane (Figure 9).

We previously showed that free flavins, reduced by the cytosolic Fre enzyme in the presence of NADH, allow an efficient reduction of the MsrQ heme. ${ }^{20}$ However, from a physiological point of view, such flavin reductase activity using free flavins is somehow problematic. First, the availability of free flavins in the cells is still not known. Second, free reduced flavins potentially exhibit broad and unspecific reactivities with redox enzymes and also with $\mathrm{O}_{2}$, leading to the formation of reactive oxygen species. ${ }^{42}$ Although it was proposed that the formation of a complex between Fre and MsrQ could limit the diffusion of free reduced flavins, ${ }^{20}$ as such it might not be sufficient to avoid these harmful and unspecific reactions within the cell. Our present data demonstrate that Fre can reduce the heme of MsrQ in the absence of free flavins, using the FMN cofactor of MsrQ (Figure 9A). This was demonstrated by the following evidences. $i$ ) In the presence of NADH, the MsrQ heme can be totally reduced by catalytic amount of Fre and in the absence of free added flavin in the reacted solutions (Figure 6). This was shown on the two different MsrQ forms studied here, purified with a His-tag (MsrQ-Tag) or after a TEV cleavage of the MsrQ-GFP fusion (MsrQ), which both contain a 1 to 1 stoichiometric amount of FMN and heme. ii) The same experiments, but in the presence of the MsrQ H151A mutant, which has lost the FMN 
cofactor, showed no significant heme reduction compare to the WT (Table 4). This suggests that the reaction is specifically associated with the MsrQ FMN cofactor, the heme in the mutant been still reducible after addition of free flavins (Figure 7). iii) The kinetic of MsrQ heme reduction catalyzed by Fre exhibits a Michealis-Menten dependence on MsrQ concentrations, with a $\mathrm{K}_{m}$ values of about $3 \mu \mathrm{M}$, in the range of the $\mathrm{K}_{d}$ value determined by SPR for the formation of the Fre-MsrQ complex (Figure 8 and ${ }^{20}$ ). This suggests that in the absence of free flavins, heme reduction occurs after formation of a Fre-MsrQ complex. On note, the maximum velocity and $\mathrm{K}_{m}$ values are only slightly affected by the presence of a $\mathrm{C}$ terminal extension on MsrQ, a eight His tag, or a entire GFP protein (Table 4). Remarkably, in all the cases, the maximum velocity is of the same order of magnitude than the Fre activity with NADH and free FMN as substrates (Table 4). Thus, the reduction of MsrQ by Fre in the absence of free flavins is a very efficient process, and not a residual activity. iv) Finally, EPR spectroscopy shows that MsrQ can accommodate a flavin semiquinone form. Whereas this one electron reduced flavin is present in a low amount in the oxidized MsrQ, it nevertheless suggests that the protein can stabilized this radical species. This is in agreement with the fact that the FMN cofactor acts as an electron relay allowing a coupling between an obligate two electrons donor, NADH, and a one-electron acceptor, the b-type heme (Figure 9A).

Such activity is unprecedented for a flavin reductase enzyme. It implies that Fre is able to use the MsrQ FMN cofactor as a substrate to reduce it in its active site in the presence of NADH (Figure 9A). Previous investigations showed that Fre catalyzes the reduction of flavins by $\mathrm{NAD}(\mathrm{P}) \mathrm{H}$ by positioning in its active site these two substrates in such a way to favor the hydride transfer from the C-4 atom position of the NADH nicotinamide moiety to the N-5 atom of the flavin isoalloxazine ring. ${ }^{34,37,40}$ The STEAP structures show that the flavin cofactor is located rather on the surface of the cytosolic side of the transmembrane domain. ${ }^{41}$ One can hypothesis that during the reduction by Fre, the FMN cofactor moves from its MsrQ binding site toward the Fre substrates cavity (Figure 9A). Such a mechanism could be favored by the formation of the Fre-MsrQ complex, as observed here (Figure 8) and in ${ }^{20}$. This FMN motion might only concern its isoalloxazine ring. Its ribitol phosphate moiety might remain tightly anchored to MsrQ, making FMN a still tightly bound cofactor, as observed after several chromatographic steps for MsrQ purification. This is also supported by the fact that Fre active site was shown to only recognize the isoalloxazine ring of the flavin (Figure 9B), ${ }^{38,40,44}$ and that, as discussed above, the MsrQ H151 residue could interact with the ribitol phosphate moiety of the FMN cofactor. Nevertheless, the FMN cofactor does not seem to contribute to the formation of the MsrQ/Fre complex (Figure 8). 
Finally, the specificities highlighted here for the reduction of MsrQ by Fre strongly supports a new physiological function for the E. coli flavin reductase as a cytosolic electron donor of the MsrPQ system, involved in $\mathrm{HOCl}$ detoxification. Also, this work reveals new catalytic properties within this protein superfamily FRD, which might concern other members such as the eukaryotic STEAP enzymes.



A.

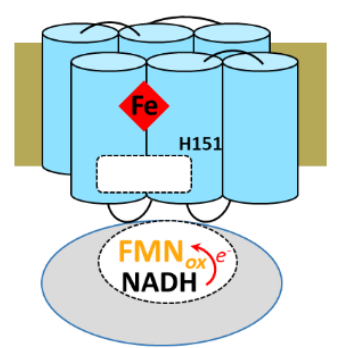

II)

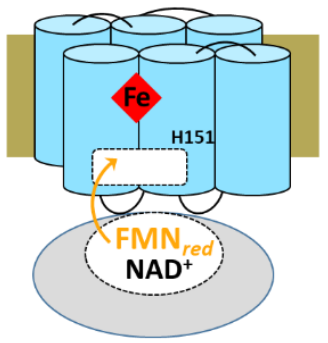

III)

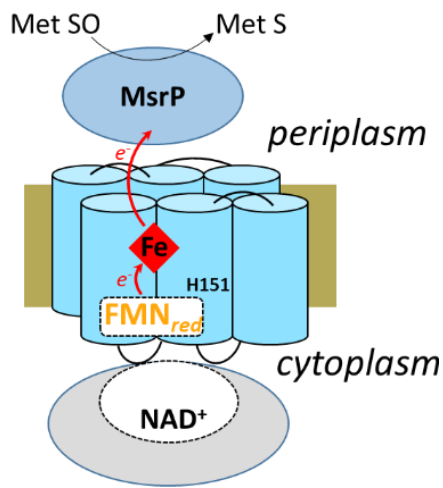

IV)

B.

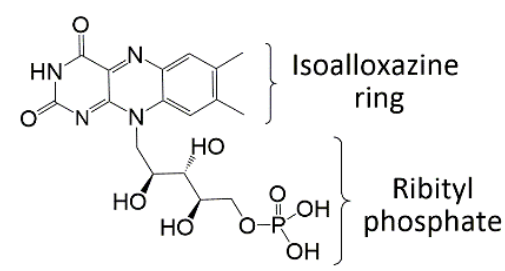

Figure 9. A) Proposed reduction mechanism of the membrane-bound flavocytochrome MsrQ by the cytosolic flavin reductase Fre. The electron transfer mechanism from the cytoplasmic NADH to the distal heme of MsrQ involves the following steps: I) Fre specifically interacts with MsrQ, close to the FMN binding site. II) The FMN moves from MsrQ to the Fre active site, where it interacts through its isoalloxazine ring and then is reduced by NADH. III) The FMN hydroquinone goes back to its MsrQ binding site, and reduces the heme thanks to its semiquinone intermediate form. IV) The reduced heme transfers the electron to the periplasmic MsrP enzyme, allowing catalysis of Met-SO reduction. B) Structure of oxidized FMN molecule, with the isoalloxazine ring and ribityl phosphate moieties. 


\section{METHODS}

Chemicals and Reagents. LMNG (lauryl maltose neopentyl glycol) was obtained from Anatrace. All other chemicals were from Sigma-Aldrich. The recombinant flavin reductase Fre from E. coli (mass 26,242 Da) was overexpressed and purified to homogeneity as described previously. ${ }^{43}$ Fre concentration was determined by the Bradford method (BioRad). The specific activity of the purified Fre was 122,000 units/mg using NADPH and riboflavin as substrates. ${ }^{43}$ The concentration of the MsrQ proteins were determined with the Pierce $^{\mathrm{TM}}$ BCA or Modified Lowry Protein Assay Kits (Thermo Fisher Scientific).

Expression and purification of MsrQ forms. MsrQ WT and H151A mutant were overexpressed using a similar protocol to that described previously, ${ }^{20}$ except using LMNG instead DDM as the detergent to solubilize the membranes. The pET28-YedZ-GFP plasmid encodes for the MsrQ (YedZ) protein from E. coli MG1655 fused on its C-terminal side to a GFP-His tagged protein. ${ }^{27}$ A TEV cleavage site is present between MsrQ and GFP. BL21(DE3) $\Delta 2.1$ pET28-YedZ-GFP cells were grown aerobically with $180 \mathrm{rpm}$ shaking in TB media at $37^{\circ} \mathrm{C}$. At an $\mathrm{OD}_{600 \mathrm{~nm}}$ of about 2 , the cells were cooled down to $20^{\circ} \mathrm{C}$ and $0.5 \mathrm{mM}$ of IPTG was added. The culture was grown overnight at $20^{\circ} \mathrm{C}$ and the cells were pelleted by centrifugation. Cell lysis was carried out in $50 \mathrm{mM}$ Tris- $\mathrm{HCl} \mathrm{pH} 8.0$ supplemented with complete protease inhibitors (Roche) at $4^{\circ} \mathrm{C}$ using a Microfluidizer M-110P at 15,000 psi (Microfluidics international). The lysate was centrifuged at 8,000 x g for 15 minutes and the supernatant was further centrifuged at $235,000 \mathrm{x} \mathrm{g}$ for 45 minutes at $4{ }^{\circ} \mathrm{C}$. The membrane fraction was resuspended in $50 \mathrm{mM}$ Tris- $\mathrm{HCl} \mathrm{pH} 8.0$ and stored at $-80^{\circ} \mathrm{C}$ until used. $100 \mathrm{mg}$ of the membrane fraction were diluted to $5 \mathrm{mg}^{-\mathrm{mL}^{-1}}$ in $50 \mathrm{mM}$ Tris- $\mathrm{HCl}, \mathrm{pH} 8.0$ and solubilized by the addition of $0.5 \%(\mathrm{w} / \mathrm{v}) \mathrm{LMNG}$ and incubation on a rotating wheel for 3 hours at $4{ }^{\circ} \mathrm{C}$. After centrifugation at $235,000 \mathrm{x} \mathrm{g}$ for $40 \mathrm{~min}$, the supernatant containing the solubilized proteins was mixed overnight at $4^{\circ} \mathrm{C}$ with $10 \mathrm{~mL}$ of Ni-NTA Agarose resin (Qiagen) pre-equilibrated with $50 \mathrm{mM}$ Tris- $\mathrm{HCl} \mathrm{pH} 8.0,150 \mathrm{mM} \mathrm{NaCl}, 0.015 \%$ LMNG. The MsrQ-GFP fusion was eluted from the resin with Buffer A (50 mM Tris- $\mathrm{HCl}$ pH 8.0, $150 \mathrm{mM}$ $\mathrm{NaCl}, 0.004 \%$ LMNG, $250 \mathrm{mM}$ imidazole). After desalting on a PD10 column (GE Healthcare) with buffer A (50 mM Tris- $\mathrm{HCl} \mathrm{pH} 8.0,150 \mathrm{mM} \mathrm{NaCl}, 0.004 \%$ LMNG), the GFP was cleaved off after an overnight incubation at room temperature with a His-tagged TEV protease. Removal of GFP and TEV was performed by a further purification on a NiNTA agarose column equilibrated with buffer A. The unbound fraction, which contained the 
MsrQ protein, was eluted with buffer A and further dialyzed against $50 \mathrm{mM}$ Tris- $\mathrm{HCl} \mathrm{pH}$ 8.0; 0.004\% LMNG. The dialyzed fraction was loaded onto a Mono-Q column (GE Healthcare) pre-equilibrated with the same buffer. The MsrQ protein was recovered in the flow-through fraction and stored at $4^{\circ} \mathrm{C}$ until used.

Another construction was also used to over-express and purify the MsrQ WT and H151A mutant forms. In these constructs, a non-cleavable tag with eight histidine residues was added at the C-terminal side of MsrQ (-EKLAAHHHHHHHH). Overexpression, membrane preparation and solubilization of this MsrQ form, termed here MsrQ-Tag, were carried out following the procedure described for MsrQ-GFP. Purification was performed thanks to a single Ni-NTA column, using the protocol reported above for MsrQ-GFP. Following Ni-NTA elution, the MsrQ-Tag protein was desalted using a PD10 column equilibrated with $50 \mathrm{mM}$ Tris/HCl pH 8.0, $0.004 \%$ LMNG.

Heme extinction coefficients. The extinction coefficients of the heme prosthetic group in MsrQ were determined on the Soret and $\alpha$ absorption bands. Reduction of MsrQ was carried out under anaerobiosis using sodium dithionite. The heme content of MsrQ was measured by the pyridine hemochromogen assay. ${ }^{45}$ Briefly, $60 \mu \mathrm{L}$ of a MsrQ solution were mixed with $60 \mu \mathrm{L}$ of a solution containing, at final concentration, $0.2 \mathrm{M} \mathrm{NaOH}$ and $40 \%(\mathrm{v} / \mathrm{v})$ pyridine. Then, few grains of solid sodium dithionite were added. The heme concentration was determined on the $\alpha$ peak of the reduced pyridine hemochromogen, using an extinction coefficient at $556 \mathrm{~nm}$ of $34.7 \mathrm{mM}^{-1} \mathrm{~cm}^{-1},{ }^{45}$ and on the basis of the difference spectra between the reduced and oxidized bispyridine heme $(\Delta \mathrm{A} 556-538 \mathrm{~nm})$ using a difference extinction coefficient of $24 \mathrm{mM}^{-1} \mathrm{~cm}^{-1}$. 45

Flavin contents. Identification and quantification of the MsrQ flavin content were carried out by HPLC analysis. ${ }^{46}$ All the solutions were protected from light with aluminum foils. MsrQ proteins were diluted to $0.5-10 \mu \mathrm{M}$ in $5 \mathrm{mM}$ ammonium acetate, $\mathrm{pH} 6.5$ (200 $\mu \mathrm{L}$ final volume), incubated at $96^{\circ} \mathrm{C}$ for $5 \mathrm{~min}$ and then cooled down $10 \mathrm{~min}$ in ice. The denatured proteins were eliminated by centrifugation, $15,000 \mathrm{x} \mathrm{g}$ for $10 \mathrm{~min} \mathrm{~g}$ at $4^{\circ} \mathrm{C}$, and 100 $\mu \mathrm{L}$ of the supernatant solution were injected onto an HPLC analytical reverse phase C18 column (4.6 x $250 \mathrm{~mm}$ ) kept at $35^{\circ} \mathrm{C}$, using an Agilent 1260 Infinity device. The HPLC column was equilibrated at a flow rate of $1 \mathrm{~mL} / \mathrm{min}$ with $85 \% 5 \mathrm{mM}$ ammonium acetate, $\mathrm{pH}$ 6.5 and $15 \%$ methanol. The flavins were eluted with a linear gradient from 15 to $75 \%$ methanol for $20 \mathrm{~min}$ at $1 \mathrm{~mL} / \mathrm{min}$. Calibration curves were obtained by injection of $100 \mu \mathrm{L}$ of 
0.5 to $5 \mu \mathrm{M}$ commercial FAD, FMN or riboflavin solutions. The flavin peaks were identified by their UV-visible spectra and integrated from their absorbance at $266 \mathrm{~nm}$ or at $450 \mathrm{~nm}$.

Enzymatic activities. The initial enzymatic velocities were measured in the presence of $50 \mathrm{mM}$ Tris- $\mathrm{HCl} \mathrm{pH} 7.6,0.004 \% \mathrm{LMNG}$ at $20^{\circ} \mathrm{C}$ under anaerobic conditions. The reactions, in 110-220 $\mu \mathrm{L}$ final volume, were followed spectrophotometrically in a Hellma quartz high precision cell with a $10 \mathrm{~mm}$ light path. Anaerobic flavin reductase activity was measured from the decrease of the absorbance at $450 \mathrm{~nm}$ due to the reduction of free FMN $(30 \mu \mathrm{M})\left(\varepsilon_{450 \mathrm{~nm}}=12.3 \mathrm{mM}^{-1} \mathrm{~cm}^{-1}\right)$ in the presence of NADH $(250 \mu \mathrm{M})$. The reaction was initiated by adding $0.01-0.10 \mu \mathrm{g}$ of Fre. The reduction of MsrQ by Fre in the absence of free flavins was followed at $558 \mathrm{~nm}$ in the presence of $250 \mu \mathrm{M}$ of NADH. No reduction of MsrQ was observed in the absence of Fre and in the presence of NADH. The reaction was initiated by adding $0.005-0.050 \mu \mathrm{g}$ of Fre. Spectra before the addition of Fre and at the end of the reaction were recorded to assess MsrQ reduction.

Anaerobic experiments. Anaerobic experiments were carried out on a glove box (Jacomex B210) equipped with an oxymeter (Arelco Arc) and filled with a nitrogen atmosphere containing less than $2 \mathrm{ppm} \mathrm{O}_{2}$. The glove box was equipped with a UV-visible cell coupled to an Uvikon XL spectrophotometer $(0.25 \mathrm{~nm}$ bandwidth) by optical fibers (Photonetics). Before starting experiments, all the solutions were equilibrated with $\mathrm{N}_{2}$ in the glove box.

EPR and electronic absorption spectroscopies. Low-temperature (15 K) Xband EPR spectra were recorded on a Bruker EMX spectrometer equipped with an Oxford Instrument ESR 910 cryostat. Q-band EPR was carried out on a Bruker Elexsys E500 spectrometer equipped with an Oxford Instrument CF935 Cryostat adapted to an ER6106 QT resonator. Spin intensity measurements were performed by double integration of the EPR signal recorded in non-saturating conditions and comparison with a $1 \mathrm{mM} \mathrm{Cu}^{2+}$-EDTA reference sample or with a $0.56 \mathrm{mM}$ sample of horse heart myoglobin complexed with azide. The microwave frequency was calibrated with a frequency counter and the magnetic field with a NMR gaussmeter. Aerobic optical absorbance measurements were performed using a Varian Cary 50 spectrophotometer $(0.25 \mathrm{~nm}$ bandwidth) with $1 \mathrm{~cm}$ path length cuvettes.

SPR interaction assays. Surface plasmon resonance (SPR) experiments were performed on a Biacore T200 using a Series S Sensor Chip CM3 functionalized at $5 \mu \mathrm{L} / \mathrm{min}$ using HBS-P buffer from the manufacturer, as previously reported. ${ }^{20}$ Flow cell (Fc) Fc1 was functionalized with BSA using amine-coupling method and used as reference surface while 
Fc2 was functionalized with purified flavin reductase Fre using the same strategy. Fc1 and Fc2 were activated with $80 \mu \mathrm{L}$ of a 0.2 M EDC/0.05 M NHS mixture. After this step, Fc1 was functionalized with $15 \mu \mathrm{l}$ of $20 \mu \mathrm{g} / \mathrm{mL}$ BSA diluted in $10 \mathrm{mM} \mathrm{NaAc} \mathrm{pH} 4$ and Fc2 with $80 \mu \mathrm{l}$ of $60 \mu \mathrm{g} / \mathrm{mL}$ Fre diluted in $10 \mathrm{mM} \mathrm{NaAc}, \mathrm{pH}$. The remaining activated groups of all cells were blocked with $80 \mu \mathrm{L}$ of $1 \mathrm{M}$ ethanolamine. The two Fc were then treated at $100 \mu \mathrm{L} \cdot \mathrm{min}^{-1}$ with $100 \mu \mathrm{L}$ of $10 \mathrm{mM} \mathrm{HCl}$ to remove non-specifically bound protein and $100 \mu \mathrm{L}$ of $50 \mathrm{mM}$ $\mathrm{NaOH} / 1 \mathrm{M} \mathrm{NaCl}$. Finally, 2785 and $3020 \mathrm{RU}$ of BSA and Fre were immobilized on Fc1 and $\mathrm{Fc} 2$, respectively. All runs were carried out at $20^{\circ} \mathrm{C}$ at a flow rate of $20 \mu \mathrm{L} \cdot \mathrm{min}^{-1}$ in running buffer (50 mM Tris-HCl pH 8, $150 \mathrm{mM} \mathrm{NaCl,} \mathrm{0.004 \%} \mathrm{LMNG,} \mathrm{0.05 \%} \mathrm{Tween} \mathrm{20).} \mathrm{Increasing}$ concentrations, ranging from 0 to $142 \mu \mathrm{M}$, of MsrQ WT and H151A were injected onto the Fre surface. After $250 \mathrm{sec}$ association, ligand dissociation was enabled for another $150 \mathrm{sec}$. Regeneration of the surface was achieved by injection of $10 \mu \mathrm{L}$ of $25 \mathrm{mM}$ EDTA, $50 \mathrm{mM}$ Glycine, $0.15 \%$ Triton, $\mathrm{pH} 12$ at $100 \mu \mathrm{L} \cdot \mathrm{min}^{-1}$. The resulting sensorgrams were reference surface corrected. The apparent affinity of compounds was determined by fitting the steady state affinity model to the plots of binding responses versus concentration, using the equation:

$$
R_{e q}=\frac{K_{A} \times C \times R_{\max }}{1+K_{A}}
$$

in which $\mathrm{R}_{\mathrm{eq}}$ is the equilibrium binding response, $K_{A}$ the equilibrium association constant $\left(K_{A}\right.$ $\left.=1 / K_{D}\right), \quad C$ the concentration of the injected analyte and $\mathrm{R}_{\max }$ the surface binding capacity.

\section{ACKNOWLEDGMENTS}

This work was supported by grants from the University Grenoble Alpes (AGIRPOLE-CBS) and from the FINOVI foundation (Fondation Innovations en Infectiologie, Lyon, France). The authors acknowledge the Labex ARCANE and CBH-EUR-GS (ANR-17-EURE0003) for a partial financial support via the CNRS, the CEA and the University Grenoble Alpes. The authors are grateful to the EPR facilities available at the French EPR network (RENARD, IR CNRS 3443) and the Aix-Marseille EPR center. 


\section{REFERENCES}

(1) Ezraty, B., Gennaris, A., Barras, F., and Collet, J.-F. (2017) Oxidative stress, protein damage and repair in bacteria. Nat. Rev. Microbiol. 15, 385-396.

(2) Kappler, U., Nasreen, M., and McEwan, A. (2019) New insights into the molecular physiology of sulfoxide reduction in bacteria, in Advances in Microbial Physiology, pp 1-51. Elsevier.

(3) Lourenço dos Santos, S., Petropoulos, I., and Friguet, B. (2018) The Oxidized Protein Repair Enzymes Methionine Sulfoxide Reductases and Their Roles in Protecting against Oxidative Stress, in Ageing and in Regulating Protein Function. Antioxidants 7, 191.

(4) Gennaris, A., Ezraty, B., Henry, C., Agrebi, R., Vergnes, A., Oheix, E., Bos, J., Leverrier, P., Espinosa, L., Szewczyk, J., Vertommen, D., Iranzo, O., Collet, J.-F., and Barras, F. (2015) Repairing oxidized proteins in the bacterial envelope using respiratory chain electrons. Nature $528,409-412$.

(5) Melnyk, R. A., Youngblut, M. D., Clark, I. C., Carlson, H. K., Wetmore, K. M., Price, M. N., Iavarone, A. T., Deutschbauer, A. M., Arkin, A. P., and Coates, J. D. (2015) Novel Mechanism for Scavenging of Hypochlorite Involving a Periplasmic Methionine-Rich Peptide and Methionine Sulfoxide Reductase. mBio (Moran, M. A., Ed.) 6, e00233-15.

(6) Gray, M. J., Wholey, W.-Y., and Jakob, U. (2013) Bacterial responses to reactive chlorine species. Annu. Rev. Microbiol. 67, 141-160.

(7) Rosen, H., Klebanoff, S. J., Wang, Y., Brot, N., Heinecke, J. W., and Fu, X. (2009) Methionine oxidation contributes to bacterial killing by the myeloperoxidase system of neutrophils. Proc. Natl. Acad. Sci. U. S. A. 106, 18686-18691.

(8) Loschi, L., Brokx, S. J., Hills, T. L., Zhang, G., Bertero, M. G., Lovering, A. L., Weiner, J. H., and Strynadka, N. C. J. (2004) Structural and Biochemical Identification of a Novel Bacterial Oxidoreductase. J. Biol. Chem. 279, 50391-50400.

(9) von Rozycki, T., Yen, M.-R., Lende, E. E., and Saier Jr., M. H. (2004) The YedZ Family: Possible Heme Binding Proteins That Can Be Fused to Transporters and Electron Carriers. J. Mol. Microbiol. Biotechnol. 8, 129-140.

(10) Sanchez-Pulido, L., Rojas, A. M., Valencia, A., Martinez-A, C., and Andrade, M. A. (2004) ACRATA: a novel electron transfer domain associated to apoptosis and cancer. BMC Cancer 4, 98.

(11) Drew, D., Sjostrand, D., Nilsson, J., Urbig, T., Chin, C. -n., de Gier, J.-W., and von Heijne, G. (2002) Rapid topology mapping of Escherichia coli inner-membrane proteins by prediction and PhoA/GFP fusion analysis. Proc. Natl. Acad. Sci. 99, 2690-2695.

(12) Brokx, S. J., Rothery, R. A., Zhang, G., Ng, D. P., and Weiner, J. H. (2005) Characterization of an Escherichia coli Sulfite Oxidase Homologue Reveals the Role of a Conserved Active Site Cysteine in Assembly and Function. Biochemistry 44, 10339-10348.

(13) Pushie, M. J., Doonan, C. J., Moquin, K., Weiner, J. H., Rothery, R., and George, G. N. (2011) Molybdenum Site Structure of Escherichia coli YedY, a Novel Bacterial Oxidoreductase. Inorg. Chem. 50, 732-740.

(14) Adamson, H., Simonov, A. N., Kierzek, M., Rothery, R. A., Weiner, J. H., Bond, A. M., and Parkin, A. (2015) Electrochemical evidence that pyranopterin redox chemistry controls the catalysis of YedY, a mononuclear Mo enzyme. Proc. Natl. Acad. Sci. 112, 14506-14511.

(15) Lee, C. C., Sickerman, N. S., Hu, Y., and Ribbe, M. W. (2016) YedY: A Mononuclear Molybdenum Enzyme with a Redox-Active Ligand? ChemBioChem 17, 453-455.

(16) Tarrago, L., Grosse, S., Siponen, M. I., Lemaire, D., Alonso, B., Miotello, G., Armengaud, J., Arnoux, P., Pignol, D., and Sabaty, M. (2018) Rhodobacter sphaeroides 
methionine sulfoxide reductase $\mathrm{P}$ reduces $\mathrm{R}$ - and $\mathrm{S}$-diastereomers of methionine sulfoxide from a broad-spectrum of protein substrates. Biochem. J. 475, 3779-3795.

(17) Andrieu, C., Vergnes, A., Loiseau, L., Aussel, L., and Ezraty, B. (2020) Characterisation of the periplasmic methionine sulfoxide reductase (MsrP) from Salmonella Typhimurium. Free Radic. Biol. Med. 160, 506-512.

(18) Tarrago, L., Grosse, S., Lemaire, D., Faure, L., Tribout, M., Siponen, M. I., KojadinovicSirinelli, M., Pignol, D., Arnoux, P., and Sabaty, M. (2020) Reduction of Protein Bound Methionine Sulfoxide by a Periplasmic Dimethyl Sulfoxide Reductase. Antioxid. Basel Switz. 9.

(19) Sabaty, M., Grosse, S., Adryanczyk, G., Boiry, S., Biaso, F., Arnoux, P., and Pignol, D. (2013) Detrimental effect of the 6 His C-terminal tag on YedY enzymatic activity and influence of the TAT signal sequence on YedY synthesis. BMC Biochem. 14, 28.

(20) Juillan-Binard, C., Picciocchi, A., Andrieu, J.-P., Dupuy, J., Petit-Hartlein, I., CauxThang, C., Vivès, C., Nivière, V., and Fieschi, F. (2017) A Two-component NADPH Oxidase (NOX)-like System in Bacteria Is Involved in the Electron Transfer Chain to the Methionine Sulfoxide Reductase MsrP. J. Biol. Chem. 292, 2485-2494.

(21) Zhang, X., Krause, K.-H., Xenarios, I., Soldati, T., and Boeckmann, B. (2013) Evolution of the Ferric Reductase Domain (FRD) Superfamily: Modularity, Functional Diversification, and Signature Motifs. PLoS ONE (Haslam, N. J., Ed.) 8, e58126.

(22) Vermot, A., Petit-Härtlein, I., Smith, S. M. E., and Fieschi, F. (2021) NADPH Oxidases (NOX): An Overview from Discovery, Molecular Mechanisms to Physiology and Pathology. Antioxid. Basel Switz. 10, 890.

(23) Magnani, F., Nenci, S., Millana Fananas, E., Ceccon, M., Romero, E., Fraaije, M. W., and Mattevi, A. (2017) Crystal structures and atomic model of NADPH oxidase. Proc. Natl. Acad. Sci. U. S. A. 114, 6764-6769.

(24) Oosterheert, W., and Gros, P. (2020) Cryo-electron microscopy structure and potential enzymatic function of human six-transmembrane epithelial antigen of the prostate 1 (STEAP1). J. Biol. Chem. 295, 9502-9512.

(25) Oosterheert, W., van Bezouwen, L. S., Rodenburg, R. N. P., Granneman, J., Förster, F., Mattevi, A., and Gros, P. (2018) Cryo-EM structures of human STEAP4 reveal mechanism of iron(III) reduction. Nat. Commun. 9, 4337.

(26) Gasteiger E., Hoogland C., Gattiker A., Duvaud S., Wilkins M.R., Appel R.D., Bairoch A.; Protein Identification and Analysis Tools on the ExPASy Server; (In) John M. Walker (ed): The Proteomics Protocols Handbook, Humana Press (2005). pp. 571-607.

(27) Drew, D., Slotboom, D.-J., Friso, G., Reda, T., Genevaux, P., Rapp, M., Meindl-Beinker, N. M., Lambert, W., Lerch, M., Daley, D. O., Van Wijk, K.-J., Hirst, J., Kunji, E., and De Gier, J.-W. (2005) A scalable, GFP-based pipeline for membrane protein overexpression screening and purification. Protein Sci. 14, 2011-2017.

(28) Walker, F. A. (1999) Magnetic spectroscopic (EPR, ESEEM, Mössbauer, MCD and NMR) studies of low-spin ferriheme centers and their corresponding heme proteins. Coord. Chem. Rev. 185-186, 471-534.

(29) Zoppellaro, G., Bren, K. L., Ensign, A. A., Harbitz, E., Kaur, R., Hersleth, H.-P., Ryde, U., Hederstedt, L., and Andersson, K. K. (2009) Review: Studies of ferric heme proteins with highly anisotropic/highly axial low spin $(S=1 / 2)$ electron paramagnetic resonance signals with bis-Histidine and histidine-methionine axial iron coordination. Biopolymers 91, 10641082 .

(30) Griffith, J. S. (1971) Theory of E.P.R. in low-spin ferric haemoproteins. Mol. Phys. 21, $135-139$. 
(31) More, C., Gayda, J. P., and Bertrand, P. (1990) Simulations of the g-strain broadening of low-spin hemoprotein EPR spectra based on the t2g hole model. J. Magn. Reson. 1969 90, 486-499.

(32) Guigliarelli, B., Bertrand, P., More, C., Haser, R., and Gayda, J. P. (1990) Single-crystal electron paramagnetic resonance study of cytochrome c3 from Desulfovibrio desulfuricans Norway Strain. Assignment of the heme midpoint redox potentials. J. Mol. Biol. 216, 161166.

(33) More, C., Belle, V., Asso, M., Fournel, A., Roger, G., Guigliarelli, B., and Bertrand, P. (1999) EPR spectroscopy: a powerful technique for the structural and functional investigation of metalloproteins. Biospectroscopy 5, S3-18.

(34) Caillet-Saguy, C., Turano, P., Piccioli, M., Lukat-Rodgers, G. S., Czjzek, M., Guigliarelli, B., Izadi-Pruneyre, N., Rodgers, K. R., Delepierre, M., and Lecroisey, A. (2008) Deciphering the Structural Role of Histidine 83 for Heme Binding in Hemophore HasA*. $J$. Biol. Chem. 283, 5960-5970.

(35) Bruschi, M., Bertrand, P., More, C., Leroy, G., Bonicel, J., Haladjian, J., Chottard, G., Pollock, W. B., and Voordouw, G. (1992) Biochemical and spectroscopic characterization of the high molecular weight cytochrome $\mathrm{c}$ from Desulfovibrio vulgaris Hildenborough expressed in Desulfovibrio desulfuricans G200. Biochemistry 31, 3281-3288.

(36) DeRose, V. J., Woo, J. C., Hawe, W. P., Hoffman, B. M., Silverman, R. B., and Yelekci, K. (1996) Observation of a flavin semiquinone in the resting state of monoamine oxidase B by electron paramagnetic resonance and electron nuclear double resonance spectroscopy. Biochemistry 35, 11085-11091.

(37) Nohr, D., Weber, S., and Schleicher, E. (2019) EPR spectroscopy on flavin radicals in flavoproteins. Methods Enzymol. 620, 251-275.

(38) Fieschi, F., Nivière, V., Frier, C., Décout, J.-L., and Fontecave, M. (1995) The Mechanism and Substrate Specificity of the NADPH:Flavin Oxidoreductase from Escherichia coli. J. Biol. Chem. 270, 30392-30400.

(39) Fontecave, M., Eliasson, R., and Reichard, P. (1987) NAD(P)H:flavin oxidoreductase of Escherichia coli. A ferric iron reductase participating in the generation of the free radical of ribonucleotide reductase. J. Biol. Chem. 262, 12325-12331.

(40) Ingelman, M., Ramaswamy, S., Nivière, V., Fontecave, M., and Eklund, H. (1999) Crystal Structure of NAD(P)H:Flavin Oxidoreductase from Escherichia coli,. Biochemistry $38,7040-7049$.

(41) Oosterheert, W., Reis, J., Gros, P., and Mattevi, A. (2020) An Elegant Four-Helical Fold in NOX and STEAP Enzymes Facilitates Electron Transport across Biomembranes-Similar Vehicle, Different Destination. Acc. Chem. Res. 53, 1969-1980.

(42) Massey, V. (1994) Activation of molecular oxygen by flavins and flavoproteins. J. Biol. Chem. 269, 22459-22462.

(43) Nivière, V., Fieschi, F., Décout, J.-L., and Fontecave, M. (1999) The NAD(P)H:Flavin Oxidoreductase from Escherichia coli: EVIDENCE FOR A NEW MODE OF BINDING FOR REDUCED PYRIDINE NUCLEOTIDES. J. Biol. Chem. 274, 18252-18260.

(44) Nivière, V., Fieschi, F., Décout, J.-L., and Fontecave, M. (1996) Is the NAD(P)H:Flavin Oxidoreductase from Escherichia coli a Member of the Ferredoxin-NADP ${ }^{+}$Reductase Family?: EVIDENCE FOR THE CATALYTIC ROLE OF SERINE 49 RESIDUE. J. Biol. Chem. 271, 16656-16661.

(45) Barr, I., and Guo, F. (2015) Pyridine Hemochromagen Assay for Determining the Concentration of Heme in Purified Protein Solutions. BIO-Protoc. 5.

(46) Aliverti, A., Curti, B., and Vanoni, M. A. (1999) Identifying and Quantitating FAD and FMN in Simple and in Iron-Sulfur-Containing Flavoproteins, in Flavoprotein Protocols, pp 9-24. Humana Press, New Jersey. 


\section{Supporting Information}
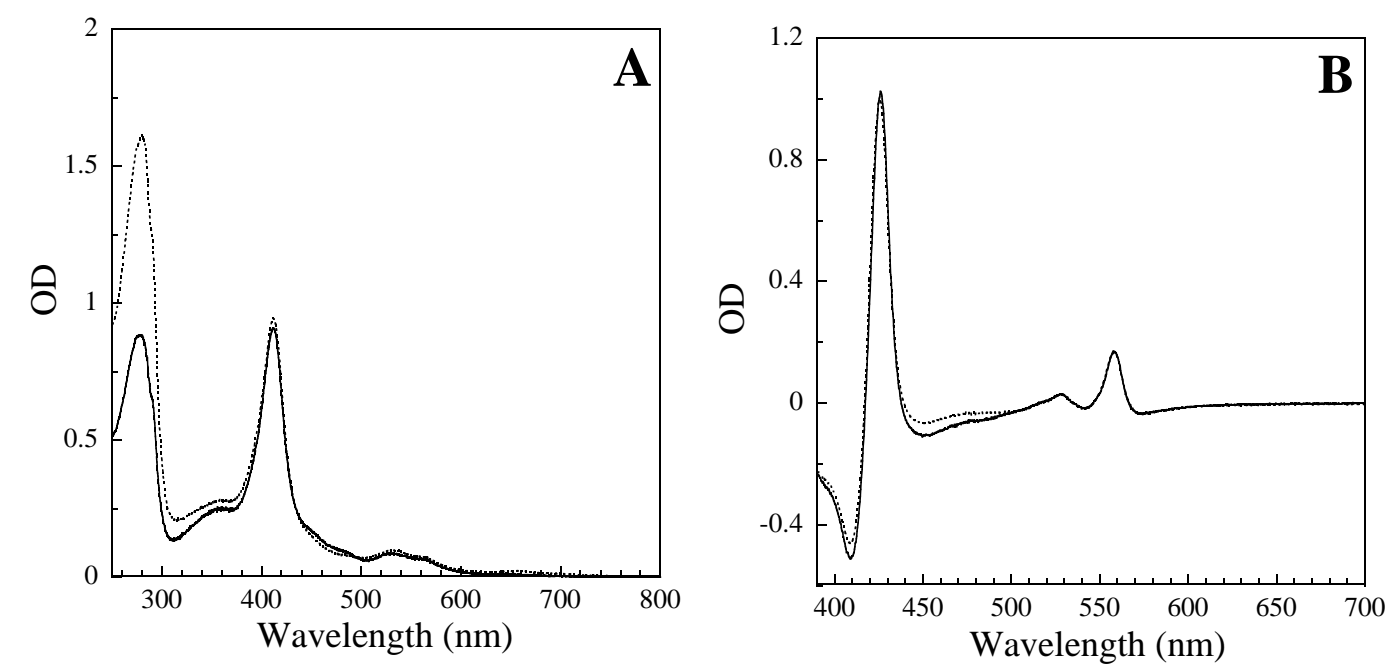

Figure S1. UV-visible spectral characterization of MsrQ-Tag WT and H151A forms at $7 \mu \mathrm{M}$ (heme concentration) in $50 \mathrm{mM}$ Tris-HCl, $\mathrm{pH}$ 8.0; 0.004\% LMNG. A) Oxidized MsrQ-Tag WT (solid line) and MsrQ-Tag H151A (dashed line). B) Reduced-minus-oxidized difference spectra of MsrQ-Tag WT (solid line) and MsrQ-Tag H151A (dashed line). 